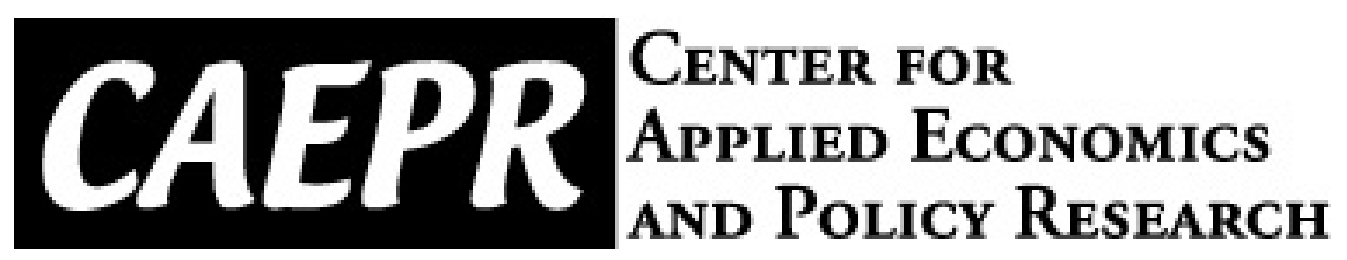

CAEPR Working Paper

\#017-2009

\title{
Fiscal and Monetary Policy Responses to Oil Price Shocks in Oil Importing Low Income Countries.
}

\author{
Michael Plante \\ Indiana University
}

August 14, 2009

This paper can be downloaded without charge from the Social Science Research Network electronic library at: http://ssrn.com/abstract=1456398.

The Center for Applied Economics and Policy Research resides in the Department of Economics at Indiana University Bloomington. CAEPR can be found on the Internet at:

http://www.indiana.edu/ caepr. CAEPR can be reached via email at caepr@indiana.edu or via phone at 812-855-4050.

(02008 by NAME. All rights reserved. Short sections of text, not to exceed two paragraphs, may be quoted without explicit permission provided that full credit, including $₫$ notice, is given to the source. 


\title{
Fiscal and Monetary Policy Responses to Oil Price
}

\section{Shocks in Oil Importing Low Income Countries.*}

\author{
Michael Plante ${ }^{\dagger}$
}

August, 2009

\begin{abstract}
This paper considers monetary and fiscal policy responses to oil price shocks in low income oil importing countries. I examine the dynamic properties and the welfare implications of a set of inflation targeting policies and a group of policies where the government provides a subsidy on household purchases of oil products and finances this subsidy through some combination of printing money and raising non-distortionary lump sum taxes. Even in the case where lump sum taxes finance the subsidy, it distorts household behavior in important ways leading to over consumption of oil products, increased trade deficits, and distortions to the labor supply. Resorting to the inflation tax to finance the subsidy leads to significant macroeconomic issues when exchange rates are flexible. The welfare gains from a policy that finances the subsidy through lump sum taxation are small compared to the policy with full pass through. For most calibrations the losses from financing the policy through the inflation tax are substantial. The welfare generated by the inflation targeting policies is close to the baseline policy with full pass through so long as the response to inflation is strong enough.
\end{abstract}

Keywords: oil prices, monetary and fiscal policy, durables, low income countries JEL Classifications: O23, E52, Q43, F41

*Date: August, 2009. Any comments would be greatly appreciated. I would like to thank my advisor Ed Buffie for many comments made about the paper. As always, I assume full responsibility for any and all errors in the paper.

${ }^{\dagger}$ Department of Economics, Ball State University, Whitinger Business Building, 2000 W. University Ave., Muncie, IN 47304, or by e-mail at mdplante@bsu.edu 


\section{Introduction}

Recent reports by the IMF and the public press have highlighted the significant challenges faced by many oil importing low income countries in the face of rising oil prices.1. These problems include, amongst others, pressure on the balance of payments, reductions in consumers' real income, and budgetary issues due to growing subsidies on petroleum products. The latter issue, in particular, has been important for many low income countries because as shown in Baig et. al (2007), Bacon and Kojima (2006), and Coady et al. (2006), many of them have been hesitant to pass through the entire price hike to consumers despite the large fiscal costs that this policy entails. For some time, many of these economies were able to successfully deal with these challenges due to a confluence of positive events, such as a concurrent rise in the prices of exported commodities. By 2008, however, many were looking at serious macroeconomic problems and were facing difficult choices about how to best respond to the oil price shocks.

A search of the literature reveals that a number of papers have been written on how policy makers should respond to oil price shocks, including but not limited to Leduc and Sill (2004), Dhawan and Jeske (2007), Plante (2009a), Bodenstein, Erceg, and Guerrieri (2008), and Bouakez, Rebei, and Vencatachellum (2008). Unfortunately, with the exception of Bouakez et al. (2008) the literature has used models suited for a large developed country, such as the United States. Low income oil importing countries, however, have a number of features that make them quite distinct from a country like the United States and this raises doubts about the applicability of the previous results.

This paper seeks to remedy this by developing a small open economy model that features currency substitution, traded and non-traded goods, household and firm demand for oil products, and a government funded subsidy on fuel products purchased by households. With the model in hand, I consider the dynamic properties and the welfare implications of several different specifications of monetary and fiscal policy when there is a surprise increase in the

\footnotetext{
${ }^{1}$ See Dudine et al. (2006), IMF (2006), IMF (2008a), and other references in the bibliography for more general information about the topic.
} 
price of oil. I consider two broad classes of policies: a set of inflation targeting policies where there is full pass through of oil prices to consumers and a set of monetary and fiscal policies which do not pass through the price increase and finance the subsidy through a combination of printing money and raising lump sum taxes.

The main findings of the paper are the following. First, regardless of how the subsidy gets financed it has a number of important distortionary effects. Vis-a-vis full pass through, subsidization leads to over consumption of oil products, larger trade deficits, and distortions in the labor supply, amongst other things. Second, the choice of how to finance the subsidy is very important for both the dynamics and the welfare results. In particular, reliance on the inflation tax in conjunction with a policy of flexible exchange rates produces significant macroeconomic problems for the country. A surprise rise in the price of oil in this case harbingers large increases in the money supply which produces a massive depreciation of the domestic currency, significant increases in all measures of inflation, and a large swing in the relative price of the non-traded good. Compared to a policy with full pass through the welfare gains from the case with lump sum taxation are generally small while the welfare losses from using the inflation tax are, for most calibrations, fairly large. Third, under an inflation targeting policy the choice of which inflation variable to stabilize matters for determinacy in the model. I show that a policy that stabilizes core or CPI inflation, as opposed to non-traded inflation, produces multiple equilibria for a wide range of calibrations of the policy rule. In terms of welfare, there appears to be only minor differences between three policies so long as it is reasonably successful in stabilizing one of the inflation variables. The rest of the paper proceeds as follows. In the next section I discuss the differences between this paper and the previous works in the literature. The third section introduces the model while the fourth section presents the results. Finally the paper concludes. 


\section{Literature Review}

This paper joins a growing number of works that use dynamic general equilibrium models to explore how oil prices affect the economy and how policy makers might respond to them. As previously mentioned, most of the work in this field has been written using models suitable for a large developed country such as the United States. This paper instead considers the case of an oil importing developing country. These countries have a number of distinguishing characteristics which set them apart from developed countries and the model used here takes this into account by incorporating traded and non-traded goods, currency substitution, and specifications of monetary and fiscal policy that are not particularly relevant to a developed country.

To my knowledge the focus on a low income oil importing country separates this paper from all previous work except that of Boukez et al. (2008). While the focus one low income countries is the same between the two papers the work here takes a different approach on several important modeling choices. First, in Bouakez et al. (2008) oil is only used in the production of a final good while in this model both households and firms use oil products. This is an important distinction to make for two reasons. First, the empirical evidence suggests that governments make distinctions between what types of oil products they subsidize, with the subsidies falling most often on products used by households. The location of the subsidy matters because of the different ways it distorts economic decisions and, consequently, how it affects the behavior of macroeconomic variables. It is also important for cases where the central bank pursues an inflation targeting policy because when households purchase oil products there is a distinct difference between the core CPI and the CPI.

Second, this paper makes a different assumption about financial markets and assets. Bouakez et al. (2008) abstract from money demand and assume that the economy is fully integrated into world capital markets. According to the IMF reports, however, the limited evidence available suggests that these countries have not heavily relied on capital markets to deal with the recent run up in oil prices. Instead, they have run down their holdings of foreign 
currency. Consequently, the model used here does not abstract from money but instead allows for holdings of domestic and foreign currency. Besides being more realistic, this is also an important consideration to take into account of when dealing with fiscal polices that may monetize the debt because the degree to which domestic and foreign currency are substitutable for each other has important implications for capital flows and inflation.

Finally, this paper considers a broader range of monetary and fiscal policy specifications but does not deal with optimal policy. Bouakez et al. (2008) is concerned with finding the optimal degree of pass through and then ranking several sub-optimal policies. Under these policies fiscal policy operates by adjusting lump sum taxes and monetary policy follows a Taylor type rule where the central bank stabilizes either the inflation rate of the price of the final good or the nominal exchange rate. Here I do not solve for the optimal policy explicitly, although I do use welfare as one measure by which to judge the usefulness of a specific policy. While I, too, consider inflation targeting schemes I also consider cases where the government may resort to printing money to clear the government budget constraint in order to finance the subsidy. This latter policy is a relevant one to consider because it is a source of financing that developing countries have often resorted to.

\section{The Model}

The model is a continuous time, perfect foresight model. Economic activity on the household side is controlled by a representative agent. The agent derives dis-utility from providing labor and gets utility from non-durables consumption and from a service flow produced using a stock of durables and oil products. The agent has access to a domestic currency, a foreign currency, and a government bond that is indexed to the CPI. Money is motivated by assuming that holdings of domestic and foreign currency reduce liquidity costs associated with spending by the consumer.

On the production side, the economy produces both a traded and non-traded good using oil and labor. The economy is small in that it is a price-taker with regards to the traded good 
and oil products. The traded good is produced by a representative firm operating under perfect competition. There is a final non-traded good that is an aggregate of differentiated, non-traded products. These differentiated goods are produced by a continuum of firms operating under monopolistic competition.

The government consists of both a fiscal authority and a monetary authority. The monetary authority may or may not be independent of the fiscal authority depending upon the exact policy specification assumed. Government expenditure consists of interest payments on outstanding debt, purchases of oil from abroad, and lump sum transfers. Government revenue comes from seigniorage and from sales of oil to firms and households. I allow for the possibility that the government subsidizes the price of oil charged to consumers.

As far as notation is concerned, the term $d X$ is the differential of the variable $X, \dot{X}$ is the time derivative of $X, X_{o}$ is the steady state value of $X$, and $\hat{X}$ is the log-differential of $X$, i.e. $\hat{X}=\frac{d X}{X}$.

\subsection{Prices}

There are a number of prices in the model and they are summarized here in order to simplify the exposition later. The traded good is the numeraire and sells domestically at a price of $e P^{t}$, where $e$ is the nominal exchange rate and $P^{t}$ is the world price of the traded good in dollars. The nominal exchange rate measures the number of units of domestic currency per 1 dollar, with the rate of depreciation of the domestic currency being

$$
\chi=\frac{\dot{e}}{e}
$$

For convenience I assume that $P^{t}$ is constant and equal to 1 so all nominal variables are deflated by $e$. 
The nominal price of the non-traded good is given by $\tilde{P}^{n}$, with an inflation rate of

$$
\pi^{n}=\frac{\dot{\tilde{P}}^{n}}{\tilde{P}^{n}}
$$

The relative price of the non-traded good is denoted as $P^{n}$ and is controlled by the differential equation

$$
\dot{P}^{n}=P^{n}\left(\pi^{n}-\chi\right)
$$

The durable good is a composite good composed of 1 unit of a traded durable and $a_{1}$ units of the non-traded good. The real price of the durable is therefore

$$
P^{d}=1+a_{1} P^{n}
$$

The composite nature of the durable good captures the notion, discussed at some length in Burstein, Neves, and Rebelo (2003), that distribution and retail costs are an important component of the prices of many tradable goods, including durables.

As mentioned earlier, the agent supplies labor to the traded and non-traded sectors. I denote the real wages received for working in these sectors as $W^{t}$ and $W^{n}$, respectively. The real price of oil in world markets is denoted as $P^{o}$. Firms always pay this price for oil but the real price paid by consumers may differ from the world price due to a subsidy. I denote this subsidized domestic price as $\mathscr{P}^{\circ}$.

\subsection{The Agent's Optimization Problem}

The agent's instantaneous utility function is of the form

$$
U\left[C\left(C^{t}, C^{n}\right), S\left(D, O^{h}\right)\right]-R\left(\frac{I^{d}}{D}-\delta_{d}\right) D-V(L) .
$$


The function $C\left(C^{t}, C^{t}\right)$ aggregates non-traded consumption goods $C^{n}$ and traded consumption goods $C^{t}$ into an aggregate measure of non-durables consumption, $C$, according to,

$$
C\left(C^{t}, C^{n}\right)=\left[C^{t \frac{\sigma_{c}-1}{\sigma_{c}}}+k_{1} C^{n \frac{\sigma_{c}-1}{\sigma_{c}}}\right]^{\frac{\sigma_{c}}{\sigma_{c}-1}}
$$

where $\sigma_{c}$ is the elasticity of substitution between the two goods and $k_{1}$ is a distribution parameter.

The function $S\left(D, O^{h}\right)$ is a production function for the service flow, with $D$ being the stock of durables and $O^{h}$ household purchases of oil products. I assume that $S$ is a CES production function of the form,

$$
S\left(D, O^{h}\right)=\left[D^{\frac{\sigma_{s}-1}{\sigma_{s}}}+\kappa_{3} O^{h \frac{\sigma_{s}-1}{\sigma_{s}}}\right]^{\frac{\sigma_{s}}{\sigma_{s}-1}}
$$

where $\sigma_{s}$ is the elasticity of substitution between the durable good and oil products while $\kappa_{3}$ is a distribution parameter.

Utility between $C$ and $S$ is aggregated by a similar CES function $U$,

$$
U\left[C\left(C^{t}, C^{n}\right), S\left(D, O^{h}\right)\right]=\frac{\left[C^{\frac{\sigma_{u}-1}{\sigma_{u}}}+\kappa_{2} S^{\frac{\sigma_{u}-1}{\sigma_{u}}}\right]^{\left(1-\frac{1}{\tau}\right)\left(\frac{\sigma_{u}}{\sigma_{u}-1}\right)}}{1-\frac{1}{\tau}},
$$

where $\sigma_{u}$ is the elasticity of substitution between $C$ and $S, \tau$ is the intertemporal elasticity of substitution, and $\kappa_{2}$ is another distribution parameter.

The $R$ term, a function of investment spending on durables, $I^{d}$, and the depreciation rate of the durable good, $\delta_{d}$, represents a form of adjustment costs known as deliberation costs, first introduced in Bernanke (1985). As discussed in Bernanke's paper, purchasing a durable good is a much more complicated and time consuming affair than purchasing a non-durable consumption good. The function $R$ reflects, in some sense, utility lost from possibly worrying about the decision and/or lost leisure from the time spent in preparation for the purchase. The functional form assumed for $R$ is

$$
R\left(\frac{I^{d}}{D}-\delta_{d}\right)=\frac{\kappa_{5}}{2}\left(\frac{I^{d}}{D}-\delta_{d}\right)^{2}
$$


where $\kappa_{5}$ is a parameter that, as I later explain, is calibrated to set the Q-elasticity of demand for the durable good.

Finally, the function $V(L)$ represents utility lost from working. The variable $L$ is total labor supplied and is equal to $L=L^{n}+L^{t}$, where $L^{n}=\int_{0}^{1} L^{n}(i) d i$ is aggregate labor supplied to the non-traded sector and $L^{t}$ is labor supplied to the traded sector. I work with a functional form which implies that in terms of utility lost from working the agent is indifferent between working in the traded and non-traded sector and only cares about aggregate labor supplied,

$$
V(L)=\kappa_{4} \frac{\left(L^{n}+L^{t}\right)^{1+\frac{1}{\mu}}}{1+\frac{1}{\mu}} .
$$

The parameter $\mu$ is the wage elasticity of labor supply and $\kappa_{4}$ is a distribution parameter.

I simplify the utility function by replacing $C$ with its indirect utility version. This is done by solving for the Marshallian demand functions of $C^{t}$ and $C^{n}$ and substituting them back into $C$, i.e. maximizing $C$ subject to the constraint that $C^{t}+P^{n} C^{n}=E$, where $E$ is real non-durables expenditure. I denote the indirect utility version as $H\left(E, P^{n}\right)$ and using this solution replace $U$ with $U^{*}\left[H\left(E, P^{n}\right), S\left(D, O^{h}\right)\right]$. Given the assumptions made on $C$ the exact form of $H\left(E, P^{n}\right)$ in this case is

$$
H\left(E, P^{n}\right)=\frac{E}{\left(1+\kappa_{1}^{\sigma_{c}} P^{n 1-\sigma_{c}}\right)^{\frac{1}{1-\sigma_{c}}}} .
$$

The law of motion for the stock of durables is

$$
\dot{D}=I^{d}-\delta_{d} D
$$

Real wealth is given by

$$
A=m+F+\frac{\tilde{P}^{C P I}}{e} b
$$

where $m=\frac{M}{e}$ is real holdings of domestic currency, $F$ is holdings of foreign currency, and $b$ is holdings of government bonds. Bonds are indexed to the CPI, $\tilde{P}^{C P I}$, which is defined 
shortly. The real flow constraint for the agent is given by

$$
\dot{A}=W^{n} L^{n}+W^{t} L^{t}+\frac{\tilde{P}^{C P I}}{e} b\left(r+\pi^{C P I}-\chi\right)+T+\Pi^{n}+\Pi^{\ell}-X\left[1+\ell\left(\frac{\psi(m, F)}{X}\right)\right]-\chi m .
$$

In the budget constraint $X$ is a term that represents real aggregate consumption expenditure,

$$
X \equiv E+P^{d} I^{d}+\mathscr{P}^{o} O^{h}
$$

The variable $\pi^{C P I}$ is the inflation rate of the CPI, $T$ is lump sum transfers from the government, $\Pi^{n}$ is rebated profits from the non-traded sector, $\ell\left(\frac{\psi(m, F)}{X}\right)$ is a function which represents liquidity costs, and $\psi(m, F)$ is a function that measures overall liquidity services provided by domestic and foreign currency. The term $\Pi^{\ell}$ is profits rebated lump sum from the firm that generates liquidity services and is equal to $X \ell\left(\frac{\psi(m, F)}{X}\right)$. This ensures that in equilibrium liquidity costs do not increase or decrease the agent's real income but instead only affect the intertemporal cost of consumption. I assume the following functional forms for $\psi$ and $\ell$,

$$
\begin{aligned}
\psi(m, F) & =\left(m^{\frac{\sigma_{m}-1}{\sigma_{m}}}+\kappa_{7} F^{\frac{\sigma_{m}-1}{\sigma_{m}}}\right)^{\frac{\sigma_{m}}{\sigma_{m}-1}} \\
\ell & =\kappa_{6}\left(\frac{\psi}{X}\right)^{1-\frac{1}{\beta}} .
\end{aligned}
$$

In $\psi$ the parameter $\sigma_{m}$ is the elasticity of substitution between domestic and foreign currency and $\kappa_{7}$ is a distribution parameter. In $\ell$ the parameter $\beta$ is the interest elasticity of demand for total liquidity (i.e. $\ell$ ) and $\kappa_{6}$ is another distribution parameter.

The agent's problem is to maximize

$$
\int_{0}^{\infty}\left\{U^{*}\left[H\left(E, P^{n}\right), S\left(D, O^{h}\right)\right]-R\left(\frac{I^{d}}{D}-\delta_{d}\right) D-V\left(L^{n}+L^{t}\right)\right\} e^{-\rho t} d t
$$

subject to equations (3), (4), and (5). Defining $\lambda_{1}$ and $\lambda_{2}$ as the multipliers on the flow 
constraints the first order conditions for the household's problem are then

$$
\begin{aligned}
V_{H} H_{E} & =\lambda_{1}\left(1+\ell-\ell^{\prime} \frac{\psi}{X}\right) \\
V_{S} S_{O^{h}} & =\lambda_{1} \mathscr{P}^{o}\left(1+\ell-\ell^{\prime} \frac{\psi}{X}\right) \\
-\ell^{\prime} \psi_{m} & =r+\pi^{C P I} \\
-\ell^{\prime} \psi_{F} & =r+\pi^{C P I}-\chi \\
\kappa_{4} L^{\frac{1}{\mu}} & =\lambda_{1} W^{n} \\
\kappa_{4} L^{\frac{1}{\mu}} & =\lambda_{1} W^{t} \\
\lambda_{2} & =\lambda_{1} P^{d}\left(1+\ell-\ell^{\prime} \frac{\psi}{X}\right)+R^{\prime} \\
\frac{\dot{\lambda}_{1}}{\lambda_{1}} & =\rho+\chi-r-\pi^{C P I} \\
\dot{\lambda}_{2} & =\lambda_{2}\left(\rho+\delta_{d}\right)-V_{S} S_{D}-R^{\prime}\left(\frac{I^{d}}{D}\right)+R .
\end{aligned}
$$

The first order condition for $E$ sets the marginal utility of consumption of non-durables equal to its marginal cost. In this case marginal cost is a function of both the marginal utility of income AND the liquidity costs that occur because spending on $E$ requires the agent to hold currency. In the first order condition for $O^{h}$, the marginal cost is a function of the marginal utility of income, the subsidized price of oil, and the liquidity costs. It is here that the subsidy directly affects household behavior because it distorts the cost of purchasing oil relative to other types of goods. This will have important effects on how much liquidity the agent desires to hold, how much the agent wishes to work, and in how much the agent desires $S$. The first order condition for $I^{d}$ is of similar form, except that the marginal cost is also a function of the marginal addition to deliberation costs, $R^{\prime}$. The first order conditions for $m$ and $F$ ensure that the marginal benefit of holding the different currencies, which occurs from reducing liquidity costs, equals the opportunity costs of both assets. Note that for $m$ this is simply the nominal interest rate on the indexed bond, $i=r+\pi^{C P I}$, while for $F$ it is the nominal interest rate minus the rate of depreciation, since the domestic currency loses value vis-a-vis the foreign currency whenever $\chi>0$. The two first order equations for $L^{n}$ 
and $L^{t}$ can be combined to give the condition that $W^{t}=W^{n}$. As the real wages are equal across sectors I simply refer to them both as $W$ hereafter. Taking into account that wages are equal across sectors the first order condition for labor then implies that

$$
\kappa_{4} L^{\frac{1}{\mu}}=\lambda_{1} W
$$

Finally the two first order conditions for $A$ and $D$ provide equations that are the continuous time versions of the Euler equations that occur in discrete time.

\subsection{Production}

Production in the traded sector is done by a representative firm operating under perfect competition. Technology in this sector is

$$
Q^{t}=A^{t}\left[L^{t^{\frac{\sigma_{t}-1}{\sigma_{t}}}}+b_{1} O^{t \frac{\sigma_{t}-1}{\sigma_{t}}}\right]^{\frac{\sigma_{t}}{\sigma_{t}-1}}
$$

where $\sigma_{t}$ is the elasticity of substitution between labor and oil and $b_{1}$ is a distribution parameter. The real unit cost function for this technology is

$$
\phi^{t}=\frac{1}{A^{t}}\left[W^{t 1-\sigma_{t}}+b_{1}^{\sigma_{t}} P^{o 1-\sigma_{t}}\right]^{\frac{1}{1-\sigma_{t}}}
$$

The factor demands for labor and oil are given by

$$
L^{t}=A^{t^{\sigma_{t}-1}} W^{t-\sigma_{t}} Q^{t}
$$

and

$$
O^{t}=A^{\sigma_{t}-1} b_{1}^{\sigma_{t}} P^{o-\sigma_{t}} Q^{t}
$$

respectively.

Production in the non-traded sector is done by a continuum of firms operating under monopolistic competition. Each firm produces a differentiated good, $Q^{n}(i)$, which it sells for 
$\tilde{p}(i)$. Technology for firm $i$ is

$$
Q^{n}(i)=A^{n}\left[L^{n}(i)^{\frac{\sigma_{n}-1}{\sigma_{n}}}+b_{2} O^{n}(i)^{\frac{\sigma_{n}-1}{\sigma_{n}}}\right]^{\frac{\sigma_{n}}{\sigma_{n}-1}}
$$

where $\sigma_{n}$ is the elasticity of substitution between oil and labor and $b_{2}$ is a distribution parameter. The real unit cost function is

$$
\phi^{n}=\frac{1}{A^{n}}\left[W^{n 1-\sigma_{n}}+b_{2}^{\sigma_{n}} P^{o 1-\sigma_{n}}\right]^{\frac{1}{1-\sigma_{n}}} .
$$

Labor demand for firm $i$ is

$$
L^{n}(i)=\phi^{n \sigma_{n}} A^{n \sigma_{n}-1} W^{n-\sigma_{n}} Q^{n}(i)
$$

while oil demand for firm $i$ is

$$
O^{n}(i)=\phi^{n \sigma_{n}} A^{n \sigma_{n}-1} P^{o-\sigma_{n}} b_{2}^{\sigma_{n}} Q^{n}(i)
$$

I assume that these goods are aggregated into a final non-traded good $Q^{n}$ by a representative firm operating under perfect competition using the technology

$$
Q^{n}=\left[\int_{0}^{1} Q^{n}(i)^{\frac{\theta^{n}-1}{\theta^{n}}}\right]^{\frac{\theta^{n}}{\theta^{n}-1}}
$$

where $\theta^{n}$ is the elasticity of substitution between the various goods. The zero profit condition for the representative firm implies that the demand for good $i$ is

$$
Q^{n}(i)=\left(\frac{\tilde{p}(i)}{\tilde{P}^{n}}\right)^{-\theta^{n}} Q^{n}
$$

and that the aggregate price index is

$$
\tilde{P}^{n}=\left[\int_{0}^{1} \tilde{p}(i)^{1-\theta^{n}} d i\right]^{\frac{1}{1-\theta^{n}}} .
$$


Prices for the individual firms, $\tilde{p}(i)$, are sticky according to setup similar to Calvo (1983). The derivations are kept to a minimum in this paper but can be found in Plante (2009c). Each firm $i$ resets its price when it receives a stochastic signal to do so. The signal follows a Poisson process with an average waiting time of $\frac{1}{\omega}$, so that $\omega$ can be calibrated to control the degree of price stickiness. I also assume that prices grow at rate equal to the steady state level of inflation. This ensures that the markup in steady state is only affected by the degree of substitutability between the goods, $\theta^{n}$, and not the steady state rate of inflation or other factors.

Given that a firm receives a signal to reset its price, the first order condition for $\tilde{p}(i)$ is found by solving the profit maximization problem,

$$
\max _{\tilde{p}(i)} \int_{t}^{\infty}\left\{\omega e^{-(s-t)(\rho+\omega)} \frac{\lambda_{1 s}}{\lambda_{1 t}}\left[\left(\frac{\tilde{p}(i)_{t} e^{\pi_{o}^{n}(s-t)}}{\tilde{P}_{s}^{n}}\right)^{1-\theta^{n}} Q_{s}^{n}-\frac{\phi_{s}^{n} Q_{s}^{n}}{P_{s}^{n}}\left(\frac{\tilde{p}(i)_{t} e^{\pi_{o}^{n}(s-t)}}{\tilde{P}_{s}^{n}}\right)^{-\theta^{n}}\right]\right\} d s
$$

The first order condition is

$\left(\theta^{n}-1\right) \int_{t}^{\infty} \omega e^{-(s-t)(\rho+\omega)} \frac{\lambda_{1 s}}{\lambda_{1 t}}\left(\frac{\tilde{p}(i)_{t} e^{\pi_{o}^{n}(s-t)}}{\tilde{P}_{s}^{n}}\right)^{1-\theta^{n}} Q_{s}^{n}=\theta^{n} \int_{t}^{\infty} \omega e^{-(s-t)(\rho+\omega)} \frac{\lambda_{1 s}}{\lambda_{1 t}} \frac{\phi_{s}^{n} Q_{s}^{n}}{P_{s}^{n}}\left(\frac{\tilde{p}(i)_{t} e^{\pi_{o}^{n}(s-t)}}{\tilde{P}_{s}^{n}}\right)^{-\theta^{n}} d s$.

I impose a symmetric equilibrium so that each firm that has the opportunity to choose its price chooses the same price $\tilde{p}^{*}$. Linearizing the first order condition around an initial steady state provides a linearized differential equation for the evolution of $\pi^{n}$,

$$
\dot{\pi}^{n}=-\omega(\rho+\omega)\left(\frac{d \phi^{n}}{\phi_{o}^{n}}-\frac{d P^{n}}{P_{o}^{n}}\right)+\rho d \pi^{n}
$$

which is just the continuous time analogue of the usual difference equation that occurs in discrete time models. Note that the rate of inflation is a function of costs denominated in terms of the non-traded good, $\frac{\phi^{n}}{P^{n}}$, not costs in terms of the traded good.

Aggregation is done linearly across firms. Equation (20) aggregated gives

$$
\int_{0}^{1} Q^{n}(i) d i=\Delta^{n} Q^{n}
$$


where $\Delta^{n}$ is a state variable measuring price dispersion in the non-traded sector,

$$
\Delta^{N}=\int_{0}^{1}\left(\frac{\tilde{p}(i)}{\tilde{P}^{N}}\right)^{-\theta^{n}} d i
$$

It can be shown that the law of motion for $\Delta$ is

$$
\dot{\Delta}^{N}=\theta_{n} \Delta^{n}\left(\pi^{n}-\pi_{o}^{n}\right)+\omega p^{*-\theta_{n}}-\omega \Delta^{n},
$$

where $p^{*}=\frac{\tilde{p}^{*}}{\tilde{P}^{n}}$. Linearization of this law of motion around an initial steady state gives

$$
\dot{\Delta}^{n}=-\omega d \Delta^{n}
$$

which implies that $\Delta^{n}$ disappears to a first order since it is a state variable.

Aggregation of equations (22) and 23) gives the aggregate demand for labor and oil,

$$
\begin{aligned}
L^{n} & =\phi^{n \sigma_{n}} A^{n \sigma_{n}-1} W^{n-\sigma_{n}} Q^{n} \Delta^{n}, \\
O^{n} & =\phi^{n \sigma_{n}} A^{n \sigma_{n}-1} P^{o-\sigma_{n}} b_{2}^{\sigma_{n}} Q^{N} \Delta^{n} .
\end{aligned}
$$

\subsection{Gross Domestic Product}

The use of intermediate inputs means that GDP is not equal to the sum of gross output in the traded and non-traded sectors. I calculate real GDP, $Q^{g}$, as

$$
Q^{g}=Q^{t}+P^{n} Q^{n}-P^{o}\left(O^{t}+O^{n}\right)
$$




\subsection{The Public Sector}

The public sector consists of the central bank and the fiscal authorities, hereafter simply the government. The balance sheet of the central bank is

$$
M=M^{d}+e Z
$$

where $M^{d}$ is the domestic component of the money supply and $Z$ is foreign exchange reserves. The growth of the money supply is

$$
\dot{M}=\dot{M}^{d}+e \dot{Z}
$$

The budget constraint for the government, in dollars, is given by

$$
\frac{\dot{M}^{d}}{e}=\frac{\tilde{P}^{C P I}}{e} r b+\left(P^{o}-\mathscr{P}^{o}\right) O^{h}+T .
$$

The consolidated government budget constraint is

$$
\dot{m}=\frac{\tilde{P}^{C P I}}{e} r b+\left(P^{o}-\mathscr{P}^{o}\right) O^{h}+\dot{Z}+T-\chi m .
$$

The government is responsible for deciding whether or not to provide a subsidy to consumers and how to finance it if they choose to provide one. The actual mechanisms by which governments set the price of petroleum products domestically varies significantly across countries.2 In some countries a government run petroleum company controls the pricing, while in others indirect taxes and subsidies of various sorts are in place. Instead of getting mired in technical details, I simply assume that the economy starts from a position where $\mathscr{P}_{o}^{o}=P_{o}^{o}$ and that on the transition path the subsidized price is a weighted average of its original steady state

\footnotetext{
${ }^{2}$ See Coady, El-Said, Gillingham, Kpodar, Medas, and Newhouse (2006) and Baig, Mati, Coady, and Ntamatungiro (2007) for more detailed discussions of the various policies in place.
} 
level and the current real price of oil,

$$
\mathscr{P}^{o}=\Xi \mathscr{P}_{o}^{o}+(1-\Xi) P^{o}
$$

The polar cases of complete and no pass through can therefore be represented by $\Xi=0$ and $\Xi=1$.

While this is simplistic, it accurately captures the important fact that the subsidy imposes a cost on the government that must be financed somehow, regardless of the actual mechanism in place. I assume that the subsidy is financed through a combination of printing money and raising lump sum taxes. More specifically, I assume that along the transition path

$$
T=T_{o}+\phi_{g}\left(P^{o}-\mathscr{P}^{o}\right) O^{h}
$$

with $0<\phi_{g}<1$. When $\phi_{g}$ is 0 the subsidy is financed entirely through use of the inflation tax, while if $\phi_{g}$ is 1 then the subsidy is entirely financed through an increase in lump sum taxes.

In cases where the government does not provide a subsidy I also consider the implications of several forms of inflation targeting policies. In these cases I assume that lump sum transfers adjust to clear the government budget constraint and that the central bank adjusts the nominal interest rate according to a policy rule of the form

$$
i=i_{o}+\alpha_{\pi}\left(\pi-\pi_{o}\right)
$$

where $\pi$ may be $\pi^{n}, \pi^{C P I}$, or $\pi^{C O R E}$.

In all cases, the government tracks several official measures of prices and their inflation rates. The core CPI is just a weighted average of the domestic price of the traded good and the non-traded good,

$$
\tilde{P}^{C O R E}=\left(e P^{t}\right)^{\gamma_{t}}\left(\tilde{P}^{n}\right)^{\gamma_{n}}
$$

where $\gamma_{t}$ and $\gamma_{n}$ are the expenditure shares of traded and non-traded consumption out of 
total non-oil spending $E+P^{d} I^{d}$. Core inflation is equal to

$$
\pi^{C O R E}=\chi+\gamma_{n} \frac{\dot{P}^{n}}{P^{n}}
$$

The CPI is a geometric weighted average of the core CPI and the price of oil paid by consumers,

$$
\tilde{P}^{C P I}=\left(\tilde{P}^{C O R E}\right)^{\gamma_{c}}\left(e \mathscr{P}^{o}\right)^{\gamma_{o}}
$$

where $\gamma_{c}$ is the share non-oil consumption expenditure out of total aggregate consumption $X$ and $\gamma_{o}$ is the share of oil consumption, $\mathscr{P}^{o} O^{h}$ out of $X$. CPI inflation can be written as

$$
\pi^{C P I}=\chi+\gamma_{c} \gamma_{n} \frac{\dot{P}^{n}}{P^{n}}+\gamma_{o} \frac{\dot{\mathscr{P}}^{o}}{\mathscr{P}^{o}}
$$

The GDP deflator, $\tilde{P}^{G D P}$, is constructed by calculating the ratio of nominal GDP to real GDP at any given point in time and GDP deflator inflation is denoted as $\pi^{G D P}$.

\subsection{Market Clearing in the Non-Traded Sector}

Output in the non-traded sector is demand determined and total output must equal total spending on the non-durable consumption good and the non-traded component of durable spending. The market clearing condition in the non-tradable sector is therefore

$$
Q^{n}=C^{n}+a_{1} I^{d}
$$

\subsection{The Current Account}

The assumptions made so far imply that $W L^{t}=Q^{t}-P^{o} O^{t}, \Pi^{n}=P^{n} Q^{n}-P^{o} O^{n}-W L^{n}$,

and $\Pi^{\ell}=X\left[\ell\left(\frac{\psi(m, F)}{X}\right)\right]$. Using these equations to substitute out $W L^{t}, \Pi^{n}$, and $\Pi^{\ell}$ from the agent's budget constraint, and then combining the resulting equation with the government budget constraint gives an equation linking the current account and net foreign asset 
accumulation,

$$
\dot{F}+\dot{Z}=P^{n} Q^{n}+Q^{t}-E-P^{d} I^{d}-P^{o}\left(O^{h}+O^{t}+O^{n}\right)
$$

If one makes use of the market clearing condition for the non-tradables sector this reduces to

$$
\dot{F}+\dot{Z}=Q^{t}-C^{t}-I^{d}-P^{o}\left(O^{h}+O^{t}+O^{n}\right) .
$$

What this states is that the economy accumulates foreign assets, either through official or private means, whenever the economy produces more of the traded good than it consumes of the traded good and oil.

\subsection{The Price of Oil}

I work under the assumption that shocks to the real price of oil are persistent, but temporary, in nature. Following a surprise shock the price declines monotonically to its steady state level according to

$$
\dot{P}^{o}=-\alpha\left(P^{o}-P_{o}^{o}\right), \alpha>0
$$

where $P_{o}^{o}$ is the initial steady state level of the real price of oil.

\subsection{Calibration}

The model is calibrated to an initial steady state with parameter and starting values chosen to represent a low income oil importing country. A table at the end of the text contains the starting values and settings for the deep parameters. The following gives a brief discussion about some of the calibration choices with the appendix explaining the procedure in more detail.

- Elasticity of substitution between $C$ and $S\left(\sigma_{u}\right)$, Intertemporal Elasticity of Substitution $(\tau)$ Whether or not $C$ and $S$ are compliments, substitutes, or separa- 
ble depends upon the magnitudes of both $\tau$ and $\sigma_{u}$. More specifically, $C$ and $S$ are compliments, separable, or substitutes as $\tau-\sigma_{u}$ is greater than, equal to, or less than zero. Unfortunately, estimates of these parameters are sparse and imprecise, even for developed countries. For a baseline case I set $\tau=\sigma_{u}=\frac{1}{2}$ so that $C$ and $S$ are separable.

- Elasticity of substitution between $C^{t}$ and $C^{n}\left(\sigma_{c}\right)$ The value of $\sigma_{c}$ controls the substitutability between the traded and non-traded, non-durables consumption goods. For the case where $C$ and $S$ are separable, $\sigma_{c}$ and $\tau$ control whether or not $C^{t}$ and $C^{n}$ are substitutes, separable, or compliments, in a manner analogous for $\sigma_{u}$ and $\tau$. For the baseline case I set $\sigma_{c}=\frac{1}{2}$ so that utility between the two goods is separable.

- Elasticity of substitution between $D$ and $O^{h}\left(\sigma_{s}\right)$ A relatively small value for this parameter is justified on two grounds. First, it is very difficult to substitute towards more fuel efficient durables in the short run, even in developed countries. Second, small (large) values for this parameter imply a low (high) price elasticity of demand for $O^{h}$. Large values of $\sigma_{s}$ therefore lead to large swings in the use of oil, and this has not been seen in the data. With this in mind, I calibrate $\sigma_{s}$ to $\frac{1}{4}$.

- Time preference rate $(\rho)$. The time preference rate pins down the steady state real interest rate. I choose a value of .05 for this parameter.

- Elasticity of substitution between domestic and foreign currency $\left(\sigma_{m}\right)$ and Interest rate elasticity of liquidity $(\beta)$ The settings for these two parameters jointly determine the interest rate elasticities of domestic currency, foreign currency, and total demand for liquidity services. The interest rate elasticity of foreign currency is positive, 0 , and negative as $\sigma_{m}>=<\beta$. With this in mind I consider as a baseline case the calibration where $\beta=\frac{1}{4}$ and $\sigma_{m}=\frac{3}{4}$, and alternative calibrations where $\sigma_{m}$ is equal to $\frac{1}{4}$ and $\frac{3}{2}$.

- The q-elasticity of durables spending $(\Omega)$. The parameter $\kappa_{5}$ in the function $R$ can be calibrated by choosing a value of the q-elasticity of durables spending, which I label as $\Omega]^{3}$ Up to a first order approximation, this parameter controls the size of

\footnotetext{
${ }^{3}$ More specifically, it can be shown that in a steady state $\kappa_{5}=\frac{P^{d} V_{E}}{\Omega \delta}$.
} 
the initial jump in spending on durables when there is an oil price shock, with larger values allowing for a large jump. Unfortunately, the literature has generally resorted to guessing its value. My baseline calibration works with a value of 3 .

- Speed of Price Adjustment in the Nontradables Sector ( $\omega)$. The average life of a price quote is $\frac{1}{\omega}$. I choose a value of 2 so that on average prices are not reset for half a year.

- Degree of substitutability between non-traded goods $\left(\theta^{n}\right)$ The value of $\theta^{n}$ controls the markup of price over marginal cost in the non-traded sector. Settings for this are over the map, even for developed countries where there is more data. I choose a value of 12 so that the markup is small but not negligible.

- Speed of Adjustment of Oil Prices $(\alpha)$ Estimates for this parameter exist for monthly and quarterly data. Pre-86 data suggest a value between .95 and 1 for the corresponding $\mathrm{AR}(1)$ coefficient while post-86 data suggest a value around .80 . This corresponds to a range for $\theta$ between .20 and 0 . I choose the conservative value of .10 .

- Elasticity of substitution between oil and labor ( $\sigma_{t}$ and $\sigma_{n}$ ) Although empirical evidence for these elasticities for traded and non-traded sectors is non-existent, these parameters can be calibrated to match the price elasticity of oil demand for firms. A variety of studies using more aggregated data suggest that these elasticities are generally small, reflecting the difficulties of substituting for oil products in the short run. Given the sparsity of data, I set $\sigma_{t}=\sigma_{n}$ to keep the two sectors symmetric in this regard and use a value of .50 .

- Shares of oil used in production Data on aggregate use of oil by all firms suggests a value of anywhere between 2 to around 10 percent of GDP, depending up on the country and the time frame examined. For the baseline calibration I choose a setting of $P_{o}^{o} O_{o}^{n}=P_{o}^{o} O_{o}^{t}=.03$ but will consider other cases in the sensitivity analysis. 


\subsection{Solution Method}

I solve the model by deriving the core dynamic system of differential equations, the variables of which vary depending up on the policy considered. I then perform a first order linearization around the initial steady state and solve the differential equations using standard techniques. In all cases I check to ensure that a solution exists and that it is unique.

\section{Results}

The results are both analytical and numerical in nature. I derive analytical solutions for as many variables as possible. I also provide a short discussion about what economic intuition suggests the results should look like. These two go a a long way in piecing together the behavior of the model but they are not comprehensive so I also rely on numerical results, which come in the form of impulse response functions and a measure that allows one to compare the welfare generated by the different policies.

In Plante (2009b) I have examined monetary policy responses to oil price shocks in a small open economy that is fully integrated into world capital markets. While there are many differences between that model and the one used here, there are also some important similarities. Due to this, some of the results carry over directly to this paper so at times I may refer to that paper.

\subsection{The Workings of the Model}

\section{Real Wages, Costs, and Inflation}

I have shown in Plante (2009b) that in economies where only labor and oil are used to produce traded and non-traded goods one can solve analytically for how the real wage $W$ changes as a function of the change in the real price of oil. As these results are a consequence of the assumptions made about production they carry over wholesale to this paper. For 
convenience's sake I repeat the most important results here again.

The real unit cost function for the traded sector,

$$
\phi^{t}=\frac{1}{A^{t}}\left[W^{1-\sigma_{t}}+b_{1}^{\sigma_{t}} P^{o 1-\sigma_{t}}\right]^{\frac{1}{1-\sigma_{t}}} .
$$

is constant and equal to one. After linearizing this around the initial steady state and performing some algebra one gets

$$
\hat{W}=\frac{b_{1}^{\sigma_{t}} P^{o 1-\sigma_{t}}}{W^{1-\sigma_{t}}} .
$$

But $b_{1}$ is calibrated using the first order conditions for $L^{t}$ and $O^{t}$ in such a way that

$$
b_{1}^{\sigma_{t}}=\frac{O_{o}^{t} P_{o}^{o \sigma_{t}}}{L_{o}^{t} W_{o}^{\sigma_{t}}},
$$

so substituting this in gives

$$
\hat{W}=\frac{\zeta_{o}^{t}}{\zeta_{l}^{t}} \hat{P}^{o}
$$

where $\zeta_{o}^{t}$ and $\zeta_{l}^{t}$ is the cost share of oil and labor, respectively, in the traded sector. Linearizing the cost function $\phi^{n}$ around the steady state and substituting in the solution for $W$ gives

$$
d \phi^{n}=\eta \hat{P}^{o}
$$

where

$$
\eta=\frac{P^{o} O^{n}}{Q^{n}}\left(1-\frac{\frac{\zeta_{o}^{t}}{\zeta_{l}^{t}}}{\frac{\zeta_{o}^{n}}{\zeta_{l}^{n}}}\right),
$$

and $\zeta_{o}^{n}$ and $\zeta_{l}^{n}$ are the cost shares of oil and labor in the traded sector.

This result shows that it is possible for $\phi^{n}$ to rise or fall when the price of oil rises depending upon the sign of $\eta$. This term is positive when ratio of the cost share of oil to labor is higher in the non-traded sector and negative when the ratio is lower in the non-traded sector. The intuition behind this is that when $\eta$ is positive the fall in $W$, which is pinned down by 
the characteristics in the traded sector, is not enough to override the positive effect that the rise in $P^{o}$ has on $\phi^{n}$. If $\eta$ is negative then the drop in $W$ is so large that it overwhelms the increase due to $P^{o}$ and reduces $\phi^{n}$. Under the baseline calibration $\eta$ is positive so $\phi^{n}$ rises whenever the price of oil rises.

Inflation in the non-traded sector is a function of costs in the non-traded sector in terms of the non-traded good, i.e. $\frac{\phi^{n}}{P^{n}}$. This can be seen in the linearized differential equation governing $\pi^{n}$,

$$
\dot{\pi}^{n}=-\omega(\rho+\omega)\left(\frac{d \phi^{n}}{\phi_{o}^{n}}-\frac{d P^{n}}{P_{o}^{n}}\right)+\rho d \pi^{n} .
$$

The solution for $\phi^{n}$ has already been given so if we can figure out what happens to $P^{n}$ after a shock we will have some idea of what happens to non-traded inflation.

As $\tilde{P}^{n}$ is pre-determined at any point in time the initial change in $P^{n}$ after a shock will always be $\hat{P}^{n}=-\hat{e}$. It is through this mechanism that monetary policy affects inflation in the non-traded sector. This is true because changes in the nominal exchange rate affect the domestic price of oil that the non-traded firm must pay. If the domestic currency appreciates (depreciates) then the price of oil drops (rises) for the non-traded firm in a way that does not affect the traded sector, since the price of the traded good varies directly with the nominal exchange rate. For example, if $\phi^{n}$ rises then a policy maker who wants to keep $\pi^{n}$ at close to its initial steady state level will need to cause a currency appreciation, as this will lower the cost of purchasing oil for the non-traded firm vis-a-vis its own price.

\section{Consumer Behavior}

Good intuition about how increases in the price of oil affect consumer behavior can be had by explicitly thinking about several specific forces that come into play.

- Income Effects Increases in the price of oil directly reduce the real income of the consumer and leads to cutbacks in spending on all goods and increases in the supply of labor.

- Substitution Effects Increases in the price of oil raise the cost of producing $S$ for the agent pushing for reductions in $S$. Substitution effects between $C$ and $S$ then influence 
the behavior of $C$ along the transition path.

- Effects on the Current Account The agent can smooth consumption of tradable goods by running trade deficits (surpluses) when the price of oil is temporarily high (low). This necessary capital inflow (outflow) occurs by by decreasing (increasing) the stock of foreign currency on hand.

- Effects on Output in the Non-traded Sector Output in the non-traded sector is demand determined so changes in the pattern of spending on non-traded goods can increase or decrease the level of production in this sector.

- Effects on Labor Supply On the transition path the change in total labor supply is

$$
\hat{L}=\mu\left(\hat{\lambda}_{1}+\hat{W}\right)
$$

While the change in wages pushes for a decrease in the supply of overall labor, changes in the marginal utility of income will push for increased labor supply. The overall effect is magnified by the size of $\mu$.

\section{Interest Elasticities and Money Demand}

One helpful method for understanding the behavior of the holdings of domestic and foreign currency is to examine the interest elasticities for the demand of liquidity, $\psi(m, F)$, domestic currency, and foreign currency. The first order conditions for $m$ and $F$ can be used to solve for these three elasticities,

$$
\begin{aligned}
\frac{\hat{\psi}}{\hat{i}} & =-\beta \zeta_{m} \\
\frac{\hat{m}}{\hat{i}} & =-\left(\sigma_{m} \zeta_{f}+\beta \zeta_{m}\right) \\
\frac{\hat{F}}{\hat{i}} & =\zeta_{m}\left(\sigma_{m}-\beta\right),
\end{aligned}
$$

where $\zeta_{m}$ and $\zeta_{f}$ are the shares of liquidity services provided by domestic and foreign currency, respectively. $\left.\right|^{4}$

\footnotetext{
${ }^{4}$ Manipulation of the first order conditions for $m$ and $F$ evaluated at a steady state shows that $\zeta_{m}=$
} 
In the special case where $\zeta_{f}=0$, the interest elasticity of liquidity demand is equivalent to the interest elasticity of demand for domestic currency and is equal to $\beta$. In the case where both $m$ and $F$ are held, the interest elasticity of demand for domestic currency reflects both changes in the overall demand for liquidity and substitution away from the domestic to the foreign currency. The former effect is captured by the $\beta \zeta_{m}$ term while the latter effect is

captured by the $\sigma_{m} \zeta_{f}$ terms. Note that the higher $\sigma_{m}$ is the more responsive $m$ will be to changes in the nominal interest rate because the easier it is to substitute away from $m$ towards $F$.

The interest elasticity of demand for total holdings of currency is foreign currency is influenced by two forces. One is the fact that the higher interest rates cause substitution towards $F$ from $m$, while the other is that higher interest rates bring about lower demand for overall liquidity. If the substitution effect dominates, i.e. $\sigma_{m}>\beta$ then the interest elasticity of demand for foreign currency is positive. The higher $\sigma_{m}$ is the greater the interest elasticity and the more the agent will substitute away from domestic to foreign currency.

\subsection{Impulse Response Functions}

The analytical results and the intuitive explanations go a long way in suggesting how the model's variables will behave on the transition path but they are limited in nature. To get a more complete picture I turn towards numerical results and examine the impulse response functions of the model's variables assuming that the economy is hit by a surprise 20 percent rise in the price of oil at time 0 .

The impulse response functions for most variables show the percentage deviations from their initial steady state values. The graphs for the subsidy, the trade balance, and the rate of change of holdings of foreign currency show their actual value (i.e. units of real GDP, since initial GDP is set to unity). For the inflation and interest rates the graphs show the actual value along the transition path. Time is recorded on the $\mathrm{x}$-axis with each unit corresponding

$\frac{i_{o} m_{o}}{i_{o} m_{o}+\rho F_{o}}$ and $\zeta_{F}=\frac{\rho F_{o}}{i_{o} m_{o}+\rho F_{o}}$. 
to a year. I report two versions of the responses for $E, P^{d} I^{d}$, and $X$. The first is the actual value of the variable and the second is one labeled (fix), which fixes prices so that relative price movements do not affect the measurement of spending. The latter is useful as a measure of real spending since it abstracts from relative price movements. The former is useful because it is the actual value that matters for money demand, amongst other things. For discussing the results I split the policies into two main groups. On the one hand are the policies where the government provides the subsidy and on the other are the inflation targeting policies. For the former group, the policy discussion revolves around whether or not to provide the subsidy and, if the subsidy is enacted, whether to fund it through the inflation tax or with lump sum taxes. For the latter, the discussion revolves around which inflation variable to stabilize and how strongly to respond to inflation.

\section{Policies with the Subsidy}

I assume that the government never intervenes in the foreign exchange market so $\dot{Z}=0$ and the nominal exchange rate can jump at any instant in time. The core dynamic system under these policies consists of equations (14), (15), (29), and (1) for the jump variables $\lambda_{1}, \lambda_{2}, \pi^{n}$, and $P^{n}$, equations (44), (3), (45) for the state variables $F, D, P^{o}$, and an equation for the state variable $\tilde{m}=\frac{M}{\tilde{P}^{n}}$. The equation for the latter is just equation 35 properly re-written in terms of $\tilde{m}$.

The baseline policy sets $\Xi=0$ and $\phi_{g}=0$, i.e. full pass through of the oil price shock and full monetization of the debt. I also consider three other cases where there is no pass through $(\Xi=1)$ and the subsidy is financed to varying degrees by changes in lump sum taxation by setting $\phi_{g}$ equal to $0, \frac{1}{2}$, or 1 .

The impulse response functions for the baseline policy are shown in Figure 1. The effects on the budget are minimal in this case and consequently the results are being driven mainly by changes in consumer and firm behavior brought about by temporarily higher oil prices. On the consumer side, the rise in the price of oil directly reduces the consumer's real income and raises the cost of producing the service flow. This results in drops in non-durables and 
durables expenditure with a larger drop in durables spending. This latter result is due both to the fact that durables and oil are compliments and to the fact that spending on durables is not constrained by the intertemporal elasticity of substitution. Spending on oil products, however, rises due to inelastic demand. Overall, aggregate consumption expenditure declines and this brings about an initial reduction in real money balances. This reduction in money balances is achieved by an initial depreciation of the currency which is important because the depreciation of the currency has important implications for the relative price of the non-traded good as well as the cost of oil in the non-traded sector. There is a sharp run down in foreign currency holdings to help finance trade deficits over the first year or so, and then holdings of foreign currency slowly climb back up to their steady state value over a number of years. Overall labor supply rises as the agent uses this mechanism to partially reduce the loss of real income form the shock. Given that output in the non-traded sector is demand determined, however, there is a sharp contraction in that sector which brings about a reduction in labor demand by firms in the non-traded sector. Labor flows into the traded sector which produces a boom in output there.

On the production side, the analytical results previously presented show that the real wage falls when the price of oil rises. In the baseline calibration the sign of $\eta$ is positive so the drop in wages is not enough to offset the rise in the price of oil in the non-traded sector. This, along with the fact that the nominal exchange rate initially depreciates, causes costs and inflation to rise in the non-traded sector. The behavior of the other inflation variables are dominated by this fact, even though CPI inflation has a strong negative component, as oil prices are falling over time.

Figure 2 shows how the results change when there is no pass through and lump sum transfers fully adjust to pay for the subsidy. For this policy and the two considered hereafter it is worthwhile trying to sort out the differences that are due to the distortions created by the subsidy and those created by how the government finances it. Examining the case when $\phi_{g}=1$ allows one to getter a clearer view of the first set since lump sum taxes are nondistortionary. 
The distortionary effects of the subsidy are most noticeable in the behavior of the different components of aggregate consumption spending. Lump sum transfers are reduced to pay for the subsidy so the agent still loses real income but the subsidy distorts the price of producing the service flow. This leads to a smaller reduction in spending on durables than before but a slightly larger drop in non-durables spending. The drop in output in the non-traded sector is less severe then the case without the subsidy, though, and therefore so is the reduction in labor demand in this sector.

Overall, however, here is larger reduction in aggregate spending. The latter result may seem paradoxical but it occurs because spending on oil products is significantly lower than the case without the subsidy and this is enough to drive down overall spending. This matters for these policies because a lower level of aggregate consumption spending leads to a greater reduction in real money balances and this can only occur if the nominal exchange rate depreciates more than previously did. Consequently the drop in the relative price of the non-traded good is more pronounced and both costs and inflation rise more in this case than without the subsidy.

Figure 3 shows the results when $\Xi=0$ and $\phi_{g}=0$ so the inflation tax finances the entire subsidy. The results here are dominated by the method of financing used. A rise in the price of oil foreshadows a significant increase in the supply of money in the future. The public knows this and immediately tries to reduce their holdings of real money balances. As with the previous cases, this can only come about by a depreciation of the currency but in this case the growth in the money supply, and consequently the size of the depreciation, is very large compared to the previous cases. As before, this leads to a reduction in the relative price of the non-traded good and a rise in costs and the inflation rate of the non-traded sector, but on a significantly increased scale. The drop in the relative price of the non-traded good causes a significant, but very temporary, boom (bust) in the non-traded (traded) sector. The rise in inflation is significant and for many years the rate of depreciation and the nominal interest rate are significantly above their steady state levels. Overall this policy causes significant dislocation in the economy. 
Figure 4 presents the results for the intermediate case when $\Xi=0$ and $\phi_{g}=\frac{1}{2}$. As might be expected the results are somewhere in between the cases where $\phi_{g}=0$ and $\phi_{g}=1$. Note that even when half the subsidy is financed by a decrease in lump sum transfers the use of the inflation tax still brings about significant macroeconomic problems. With household spending of oil products equal to five percent of GDP in the steady state a persistent rise in the price of oil requires a significant increase in government spending. Even with lump sum transfers picking up half the tab relying on the inflation tax for the other half requires a significant increase in the nominal supply of money.

The main results from the impulse response functions for this group of policies are the following. First, even without considering the issues of the subsidy, a temporary rise in the price of oil has important effects on the economy. Aggregate consumption spending falls, real money balances decline, and the nominal exchange rate depreciates causing the relative price of the non-traded good to temporarily fall. Output in the non-traded sector, being demand determined, also falls as consumer demand is temporarily low. In the baseline calibration, costs and inflation rise in the non-traded sector and because of this the other measures of inflation also rise above their steady state levels. Second, even when the subsidy is financed through non-distortionary lump sum taxes it leads to distortions in household behavior. Oil products are over consumed, trade deficits are higher, and the levels of a variety of other macroeconomic variables are different on the transition path compared to the case with full pass through. Third, when the inflation tax is used to finance the subsidy the effects are dramatic. With steady state consumption of oil products around 5 percent of GDP even a modest rise in the price of oil requires a significant stream of revenue to finance the subsidy. This requires a significant increase in the supply of money which causes a massive instantaneous depreciation of the currency, a large swing in the relative price of the non-traded good, and significant rises in the rate of inflation, the nominal interest rate, and the rate of depreciation.

\section{Inflation Targeting Policies}

Under a policy of inflation targeting the central bank pursues a goal of stabilizing some 
measure of inflation around a target value. I assume that in this case the government always passes through the oil price increase and clears the budget constraint by adjusting lump sum transfers. As the nominal interest rate is the monetary policy target, the nominal exchange rate can jump at any point in time and the nominal money supply adjusts passively based on the agent's desired holdings of real money balances. The core dynamic system here consists of equations (14), (15), (29), and (1) for the jump variables $\lambda_{1}, \lambda_{2}, \pi^{n}$, and $P^{n}$, and equations (44), (3), 45) for the state variables $F, D, P^{o}$. Real money balances is not part of the core system in this case as it is endogenously determined by the first order condition given in equation (9).

There are a number of inflation variables that the central bank could focus on stabilizing. I first examine the case where the bank stabilizes $\pi^{n}$ and then consider the use of $\pi^{C O R E}$ or $\pi^{C P I}$. While the choice of $\pi^{n}$ may seem an odd choice since most central banks focus on either CPI or core inflation, it is a useful benchmark by which to compare the other two because the workings of the model turn out to be more clean cut in this case.

\section{Stabilizing $\pi^{n}$}

I assume that the central bank implements the policy by announcing and credibly following a policy whereby they adjust the nominal interest rate according to

$$
i=i_{o}+\alpha_{\pi}\left(\pi^{n}-\pi_{o}^{n}\right)
$$

which is simply equation 38 with $\pi=\pi^{n}$.

In Plante (2009b) I have derived a number of results for the same inflation targeting policy in a small open economy that is fully integrated into world capital markets. It turns out that despite the different assumptions about financial markets made in this paper that two main results of the previous paper carry over completely to this one. First, the higher the value of $\alpha_{\pi}$ the smaller the values of $d \pi^{n}$ both initially and along the entire transition path. Second, the behavior of the nominal exchange rate under this policy depends crucially upon the sign of $\eta$. I have already shown analytically that under the baseline calibration that 
a rise in the price of oil pushes up $\phi^{n}$ since $\eta$ is positive. Costs in the non-traded sector, and consequently non-traded inflation, remain constant only if the nominal exchange rate appreciates by just the right amount. For the case when $\eta$ is negative the nominal exchange rate needs to depreciate by the just the right amount. For the baseline calibration, the fact that the exchange rate appreciates means that the relative price of the non-traded good initially rises. The path of $\chi$ must also be just right to ensure that on the transition path the costs remain constant in the non-traded sector. For cases where $\eta$ is negative the results are reversed.

The implementation of this policy requires a special adjustment of the nominal rate. Basi-

cally, the nominal interest needs to be adjusted need to be track the real interest rate on a bond indexed to $\tilde{P}^{n}$. If there were such a bond available the nominal interest rate on this bond would be

$$
i^{n}=r^{n}+\pi^{n}
$$

and a no-arbitrage condition would ensure that $i^{n}=i$. We can see immediately that a policy that keeps $\pi^{n}$ very close to its steady state level requires that $i$ be adjusted to closely track the changes in $r^{n}$, where from the arbitrage condition we know that

$$
r^{n}=r+\left(\pi^{C P I}-\pi^{n}\right)
$$

The impulse response functions in shown in figure 5 are in line with the discussion just given. The non-traded sector in the baseline case $\eta$ is positive so stabilizing $\pi^{n}$ requires the currency to appreciate in order to reduce costs for the non-traded firms. The drives up the relative price of the non-traded good and pins down the path of $\chi$, pushing it above its steady state level on the transition path. The behavior of the real variables roughly follows the behavior seen in the baseline policy, although the relative price change reduces the amount of spending on the non-traded good.

\section{Stabilizing Core or CPI Inflation}

The previous policy of stabilizing $\pi^{n}$ is one worthwhile investigating since it provides some 
useful information about the workings of the model. But in practice central banks generally focus on stabilizing either core inflation or CPI inflation. Therefore I now turn my attention to these two policies. I continue to assume that the central bank uses a rule of the form found in equation 38 but replace $\pi^{n}$ with $\pi^{C O R E}$ or $\pi^{C P I}$.

In Plante (2009b) I analyzed an inflation targeting policy that stabilized core inflation.$^{5}$ Analytical derivations provided two main results for this type of policy. The first result was that this policy produced multiple equilibria in the economy when $\alpha_{\pi}$ was greater than the share of the traded good in the CPI.

It turns out that the indeterminacy problem also occurs in this model, despite the different assumptions made about financial markets and financial assets. Unfortunately, it is not possible to derive analytically what values of $\alpha_{\pi}$ produce indeterminacy except in the extreme case where $\pi^{C O R E}$ or $\pi^{C P I}$ are fully stabilized. For cases besides this one numerical results must be used to determine whether or not the calibration of $\alpha_{\pi}$ leads to indeterminacy.

Suppose we are considering a policy that stabilizes core inflation. From the equation for the core CPI we know that if core inflation is fully stabilized it must be true that

$$
d \chi=-\frac{\gamma^{n}}{1-\gamma^{n}} d \pi^{n}
$$

Substituting this into the linearized version of the differential equation for $P^{n}$ one gets

$$
\dot{P}^{n}=\frac{1}{1-\gamma^{n}} d \pi^{n}
$$

Making use of the solution for $\phi^{n}$ derived previously the linearized equation for $\dot{\pi}^{n}$ can be written as

$$
\dot{\pi}^{n}=-\frac{\omega(\rho+\omega)}{\phi_{o}^{n}} \eta \hat{P}^{o}+\omega(\rho+\omega) d P^{n}+\rho d \pi^{n} .
$$

The differential equations for $\pi^{n}, P^{n}$ and $P^{o}$ consequently form a sub-system that can be solved independently of the other equations of the system. In this case the subsystem can

\footnotetext{
${ }^{5}$ In that paper households did not purchase oil products so there was no distinction between core and CPI inflation.
} 
be written as

$$
\left[\begin{array}{c}
\dot{\pi}^{n} \\
\dot{P}^{n} \\
\dot{P}^{o}
\end{array}\right]=\left[\begin{array}{ccc}
\rho & x 1 & x 2 \\
x 3 & 0 & 0 \\
0 & 0-\alpha &
\end{array}\right]\left[\begin{array}{l}
d \pi^{n} \\
d P^{n} \\
d P^{o}
\end{array}\right]
$$

where $x 1>0$ and $x 2$ may be greater than, less than, or equal to 0 . It can be shown that the three eigenvalues for this system are $-\alpha, \frac{1}{2}\left(\rho-\sqrt{4 x 1 x 3+\rho^{2}}\right)$ and $\frac{1}{2}\left(\rho+\sqrt{4 x 1 x 3+\rho^{2}}\right)$. There is only one state variable in the system but there are always two negative roots. Consequently, a policy that succeeds at fully stabilizing core inflation does not pin down the initial jump in either $\chi$ or $\pi^{n}$.

To see why this might be occurring remember that there is a real interest rate in terms of the non-traded sector, $r^{n}$. If $d \pi^{C O R E}$ is 0 then so also is $d i$, but then it must be true that

$$
d r^{n}=-d \pi^{n}
$$

which shows that whenever inflation rises in the non-traded sector the real interest rate falls. But, falling real interest rates imply that output in the non-traded sector is pushed above its optimal level which spurs more inflation. In this case nothing actually pins down non-traded inflation except for expectations.

While it is not possible to show that this is the case for values of $\alpha_{\pi}$ besides the extreme case of full stability, the numerical results for the baseline calibration show that the indeterminacy region occurs for empirically relevant values of $\alpha_{\pi}$. Under the baseline calibration a policy that stabilizes core inflation produces indeterminacy for values of $\alpha_{\pi}$ greater than about 2.35.

Although I do not present the analytical results here, one can also show that using CPI inflation instead of core inflation in the policy rule does not change the overall result regarding indeterminacy. In the extreme case of full stability one can again derive a sub-system in $P^{n}$, $\pi^{n}$, and $P^{o}$ and show that the eigenvalues are equivalent to those produced in the case where core inflation is stabilized 6 Numerical results for the baseline calibration shows that the

\footnotetext{
${ }^{6}$ The eigenvectors of the system differ in the two cases but the eigenvalues do not.
} 
indeterminacy boundary is near a value of $\alpha_{\pi}$ equal to 2.3 for this policy.

The second main result regarded the dynamic behavior of this policy as $\alpha_{\pi}$ approached the indeterminacy boundary. In the model in Plante (2009b) I showed that this calibration led to the policy behaving almost exactly like one which stabilized non-traded inflation. Analytical results are out of the question in this case so I must rely on numerical solutions to see if this holds true for this model. In order to consider the hypothesis I examine both policies that stabilize core and CPI inflation, and set $\alpha_{\pi}$ equal to 2.35 and 2.30 for each policy, respectively.

The impulse response functions for the two policies are shown in figures 6 and 7. A quick comparison between figures 5 and 6 show that the two are almost exactly the same. There are some minor qualitative differences in the behavior of several variables. For example, in figure 5 the rate of depreciation initially jumps up and then falls monotonically over time but under the policy that stabilizes core inflation the initial jump is smaller and the rate of depreciation rises for some period of time. This occurs because stabilization of core inflation imposes some restrictions on the behavior of $\chi$ and $\pi^{n}$ not found in the policy that stabilizes non-traded inflation.

Comparing figures 5 and 7 also reveal a number of similarities between the two policies. There is one important difference to note, though, as it will influence the welfare results later on. It appears that the policy rule is unable to fully stabilize CPI inflation even at when $\alpha_{\pi}$ is next to the upper limit. Consequently nominal interest rates are higher under this policy and, even if the result is only significant qualitatively, it brings about a reduction in real money balances larger than that found in the other two cases. Besides this results are fairly similar between this policy and the other two policies so I refer the reader to the previous discussion for more details. 


\subsection{Policy and Welfare}

Besides analytical results and impulse response functions another way to consider the merits of the various policies is to examine their implications for welfare in the model. In order to do so I calculate a kind of compensating variation term which calculates how much non-durable consumption would need to be raised or lowered along the transition path to ensure that the welfare from one policy is equal to another.

To see how this is done consider the welfare generated by two policies denoted as policy a and policy b, with policy a being the reference point. A priori there is no theoretical reason to choose one policy or another as the reference point so I choose to use the case where $\Xi=0$ and $\phi_{g}=0$. Under policy a welfare is given by

$$
\int_{0}^{\infty}\left\{U^{*}\left[H\left(E^{a}, P^{n a}\right), S\left(D^{a}, O^{h^{a}}\right)\right]-R\left(\frac{I^{d^{a}}}{D^{a}}-\delta_{d}\right) D^{a}-V\left(L^{n a}+L^{t^{a}}\right)\right\} e^{-\rho t} d t
$$

and welfare under policy b may be written in a similar manner. To calculate the compensating variation term, which I denote as $\lambda^{c}$, I re-write the welfare generated by policy $b$ as

$$
\int_{0}^{\infty}\left\{U^{*}\left[H\left(E^{b}\left(1-\lambda^{c}\right), P^{n b}\right), S\left(D^{b}, O^{h^{b}}\right)\right]-R\left(\frac{I^{d^{b}}}{D^{b}}-\delta_{d}\right) D^{b}-V\left(L^{n b}+L^{t^{b}}\right)\right\} e^{-\rho t} d t
$$

and solve for the value of $\lambda^{c}$ that makes the welfare of policy b equal to that from policy a. I do this numerically by integrating the equations from $t=0$ to $t=100$. If $\lambda^{c}$ is a positive number then the welfare is higher under policy $\mathrm{b}$ and that policy is preferred to policy a, i.e. consumption must be lowered in order to get welfare in policy b equal to that in policy a. If $\lambda^{c}$ is negative then the opposite case holds and policy a is preferred to policy b, i.e. consumption would have to be raised to get the welfare from policy b equal to policy a.

As I only solve the model accurate up to a first order approximation I also perform the same expansion on the utility function when calculating $\lambda^{c}$. Note that this is not without loss of generality, as the price dispersion term disappears in the first order expansion but 
not in higher order expansions. As I discuss shortly the price dispersion term represents the distortion that arises from sticky prices. Hence using just the first order solution reduces the premium one would place on a policy that stabilizes non-traded inflation. An important line of work for future research would solve the model up to a second order approximation to see if this is a particularly important issue or not.

To understand what drive the welfare results it is necessary to understand the different distortions which may reduce welfare. In this model there are a total of four possible distortions: sticky prices, monopolistic competition, liquidity costs, and the subsidy on the price of oil products.

The distortion from sticky prices shows up in the price dispersion term $\Delta^{n}$ that appears in the first order conditions for aggregate labor and oil demanded by firms in the non-traded sector. Price dispersion creates welfare losses by reducing the amount of aggregate output generated for given levels of labor and oil inputs.

Monopolistic competition affects the level of output produced in the non-traded sector. The degree to which this distortion is present is controlled by $\theta^{n}$. The larger $\theta^{n}$ the more competitive the sector is and the smaller the distortion. The case of perfect competition holds when $\theta^{n}=\infty$, in which case marginal cost is always equal to the aggregate price level and the distortion disappears completely.

The liquidity costs distortion makes itself known in the first order conditions for $E$, $O^{h}$, and $I^{d}$. More specifically, it is the $\left(1+\ell-\ell^{\prime} \frac{\psi}{X}\right)$ term which matters. When liquidity costs are 0 this term is exactly equal to 1 and the first order condition is equivalent to the one which would arise using a MIU specification with money and consumption separable. In all other cases the distortion is present and this impacts the agent's decision about how much to consume and work.

The last distortion is the subsidy that may be placed on oil products. This directly appears in the first order condition for $O^{h}$ and affects the marginal cost of purchasing more oil for the household. More generally, it distorts not only the decision about how much oil to use 
but also how much of the other goods to purchase and how much labor to supply.

Welfare would be maximized if all of these distortions were eliminated from the model. No policy, however, is able to accomplish all of this at once. The reason for this is that some of the distortions call for diametrically opposed policies to alleviate the welfare losses caused by them. For example, it is possible to use inflation to reduce the distortion from monopolistic competition but this conflicts with reducing price dispersion. A welfare maximizing policy would take into account the degree to which each of the distortions are present and then behave in such a way as to maximize utility subject to how important the different distortions are. If prices were very sticky, for example, then this type of policy would place a high emphasis on minimizing inflation in the non-traded sector.

While there is a large set of easily interpretable results about welfare in models with sticky prices and monopolistic competition, there is to my knowledge no results for models with all four of the distortions considered here. A priori it is not clear what types of policies will be preferred so I must rely on numerical results.

As a baseline case I consider the model under its baseline calibration where $\theta^{n}=12, \omega=2$, and $\sigma_{m}=.75$. The results for this experiment are found in table (1). I consider policies where $\Xi=0, \Xi=1$ and $\phi^{g}=.5, \Xi=1$ and $\phi^{g}=1$, and inflation targeting policies where $\alpha_{\pi}=1.50$ and the bank stabilizes either $\pi^{n}, \pi^{C O R E}$, or $\pi^{C P I}$. As shown in the table there are two policies that produce large welfare losses, the policy where $\Xi=1$ and $\phi^{g}=0$ and $\Xi=1$ and $\phi^{g}=0.50$. The former policy produces a loss of about 10 percent of a unit of consumption while the latter produces a loss of 4 percent. In ranking, the next in line are the inflation targeting policies which produce losses of around 1 percent, the policy which sets $\Xi=0$, and finally the policy with no pass through that finances the subsidy entirely through decreases in lump sum transfers.

Based on the impulse response functions it appears that policies which produce significant amounts of inflation are not preferred for the baseline calibration. In order to get a clearer picture of which policies are preferred, and why, it is best to examine how welfare varies as a function of $\theta^{n}, \omega, \sigma_{m}$, and $\alpha_{\pi}$ before getting into any discussions about the results. 
The results for these experiments are found in tables (2), (3), (4), and (5), respectively. I first consider the results for varying $\sigma_{m}$ from its baseline value of .75 to a lower value of .25 and a higher value of 1.50. This parameter controls the degree of substitutability between domestic and foreign currency with higher values leading to easier substitution. The table shows that increasing the size of $\sigma_{m}$ while holding all other parameters constant significantly reduces the desirability of those policies which call for significant increases in the money supply, i.e. the policies where $\Xi$ is 1 and $\phi_{g}$ is either 0 or .50 . For low degrees of substitutability these policies actually are preferred to the others, but for high degrees of substitutability they are very much not preferred.

The intuition behind this result is easy to get at. For high degrees of substitutability these types of policies lead to significant capital flight which brings forth higher inflation and nominal interest rates. For low degrees of substitution the benefits of having the subsidy and the reduction in the distortion from monopolistic competition override the fact that higher nominal interest rates lower money demand and raise liquidity costs. Similar intuition is behind why the losses from the inflation targeting policies grow as $\sigma_{m}$ rises. For constant values of $\alpha_{\pi}$ the policies lead to slightly higher inflation and nominal interest rates, which increases liquidity costs.

Varying $\omega$ controls the degree of price stickiness in the model, with higher values implying more flexible prices. This is important for the welfare results in two ways. First, when prices are very sticky then inflation can be used more successfully to reduce the distortion from monopolistic competition because relative price distortions remain for longer periods of time. If prices are very flexible then this ability is reduced because prices adjust very rapidly. This also matters for liquidity costs, because a more rapid adjustment in prices leads to larger spikes in inflation in the short run. This increases the distortion from liquidity costs because spikes in inflation show up as spikes in the nominal interest rate. Consequently, the the policies where $\Xi$ is 1 and $\phi_{g}$ is either 0 or .50 . become less and less preferred as prices become more and more flexible.

The value of $\theta^{n}$ controls the size of the distortion from monopolistic competition. Higher 
values of $\theta^{n}$ reduce the attractiveness of policies which generate inflation since they imply that output is closer to its efficient level than would occur with lower values of $\theta^{n}$. This reduces the benefits of having high inflation while the costs, from larger liquidity costs due to higher nominal interest rates, still remain. From table (2) we can see this intuition play out. As $\theta^{n}$ becomes increasingly large the policies which finance the subsidy through the inflation tax tend to be less and less preferred compared to the other policies. In terms of the other policies the value of $\theta^{n}$ has more modest impacts.

As a last exercise, one can also ask how welfare varies as a function of $\alpha_{\pi}$ for the various inflation targeting policies. The results for this are show in table (5). As I have discussed elsewhere, the value of $\alpha_{\pi}$ controls how volatile the inflation variable in the rule is, with higher values leading to smaller and smaller deviations of the inflation variable from its target. Given the form of the rule, though, it also is directly related to the volatility of the nominal interest rate since the rate varies directly with the inflation variable. Therefore any benefits which might arise from having more volatile inflation by reducing the distortion from monopolistic competition will conflict with keeping the nominal interest rate low and reducing liquidity costs. Under the baseline calibration of $\theta^{n}$ and $\sigma_{m}$ the affects from the liquidity costs dominate as lower values of $\alpha_{\pi}$ increase the welfare losses for all of the policies compared to higher values. The entries greater than 2 are blank for the policies that stabilize core and CPI inflation since they generate an indeterminate solution.

At first glance one might surmise that subsidizing the price of oil in the face of an oil price shock might increase welfare for the agent. The rub is that this policy needs government financing to be implementable and the choice of financing may itself create further distortions that reduce welfare. As shown in the results, if the financing is done by printing money it is only under conditions of significant price stickiness or low substitutability between domestic and foreign currency that this policy generates higher welfare than other policies considered. Unfortunately, these calibrations are unrealistic and for more realistic values it is almost always the case that the distortions generated by the policy override any benefits that might accrue to the agent. 
The results do show that if the subsidy is financed by increasing lump sum taxes then it is often slightly preferred to the other policies. There are two important caveats to this conclusion though. First, the gains are small for almost all of the calibrations. Over the entire 100 years that the utility function is integrated to solve for $\lambda^{c}$ non-durables consumption generally only needs to be raised by about .015 units. Second, in reality non-distortionary taxation is not an option for financing the subsidy. In practice the subsidy will instead be financed through the use of some type of distortionary taxation or by reducing government spending on some other item in the budget. It seems unlikely that once these effects are taken into account that welfare would be higher than it already is, and in fact it could be a great deal lower. Consequently, under a more realistic assessment the best policy, in terms of welfare, would appear to be one which fully passes through the price increase to the agent and instead focuses on stabilizing inflation and nominal interest rates.

\section{Conclusions}

This paper has examined monetary and fiscal policy responses to oil price shocks in oil importing low income countries. The model takes into account some special features of these types of economies which separate them from large developed economies that have been the focus of most previous work in the area. Instead of working with a large closed economy model the model used here is a small open economy model that incorporates currency substitution and non-traded goods. I examine a number of specifications for monetary and fiscal policy, including policies where a subsidy may be placed on household purchases of oil products.

Examination of impulse response functions show that regardless of the financing method a subsidy on the price of oil can have important effects on macroeconomic variables vis-a-vis a policy that fully passes through the price shock. When lump sum transfers are reduced to finance the subsidy it leads to over consumption of oil products by the household, increased trade deficits, distortions to the consumption decisions for other products, and distortions 
to the labor decision. Under this case the welfare results show that while this policy raises welfare for a number of calibrations the gains are minimal. In most cases the agent would need non-durable consumption raised by less then two percent of steady state levels over the entire future to make welfare equivalent between this policy and policy without the subsidy. When the government finances the subsidy through the inflation tax the effects on the economy are stark. This policy brings about an immediate and large exchange rate depreciation that distorts the relative price of the non-traded good and drives up inflation significantly. Welfare results show that only for unrealistic calibrations where the economy is highly distorted does this policy improve welfare compared to the other policies.

I have also considered cases where the government decides not to provide a subsidy but instead implements an inflation targeting policy. The results for the impulse response functions show that in this case it is possible for the monetary authority to fully stabilize non-traded inflation by properly adjusting the nominal exchange rate. Depending upon the cost shares of oil and labor in the traded and non-traded sectors it is possible that under this policy the currency appreciates or depreciates when the price of oil rises. Another important result is that policy that attempts to stabilize core or CPI inflation introduces the possibility of multiple equilibria in the economy. This result mirrors that found in Plante (2009b), which was for a small open economy fully integrated into world capital markets. Welfare results show that so long as the response to inflation is strong enough, but not so strong as to cause indeterminacy in the case of stabilizing core or CPI inflation, that the welfare generated by these policies is fairly close to the baseline case of full pass through and monetization of the debt.

Overall, the results show that a policy of subsidizing the price of oil does not appear to be welfare enhancing for the economy because the policy requires the government to finance it somehow. Even in the case where the financing is done entirely through non-distortionary lump sum taxation welfare appears to improve only slightly compared to a similar policy with full pass through. When the policy is financed through the inflation tax the effects brought about by the large increases in the money supply are almost always welfare reduc- 
ing compared to the baseline policy. While results are not available for other methods of distortionary financing, given the small gains that accrue even under non-distortionary financing it appears unlikely that welfare would be improved compared to the baseline policy. Consequently, the results suggest, at least from a macroeconomic perspective, that it is best to pass on the price hike to consumers and focus on stabilizing inflation through appropriate monetary policy. This appears feasible for a number of inflation targeting schemes or even for the baseline policy where printing money is used to finance the deficit.

Of course, this paper does not cover all of the possible avenues of research. First, it is well known that welfare results are sensitive to whether or not the model is solved accurate to a first order approximation or a higher order approximation. It would be useful to solve the model using a second order approximation to see if the inclusion of the price dispersion term creates a meaningful difference in the ranking of the various policies. Second, the model used here is highly aggregated and hence misses out on some potentially important distributional issues. While these issues are beyond the scope of this paper it may be useful from a policy making perspective to understand more clearly how welfare is affected for various income groups with and without the subsidy. 
Table 1: Welfare Under the Baseline Calibration $\left(\theta^{n}=12, \omega=2, \sigma_{m}=.75, \alpha_{\pi}=1.50\right)$

\begin{tabular}{lc} 
Policy & $\lambda^{c}$ \\
\hline$\Xi=0$ & 0 \\
$\Xi=1, \phi_{g}=0$ & -0.102 \\
$\Xi=1, \phi_{g}=.50$ & -0.037 \\
$\Xi=1, \phi_{g}=1$ & 0.015 \\
IT, $\pi^{n}$ & -0.010 \\
IT,$\pi^{C O R E}$ & -0.009 \\
IT,$\pi^{C P I}$ & -0.014
\end{tabular}

Table 2: Welfare as a Function of $\theta^{n}$

\begin{tabular}{lccccc}
$\theta^{n}$ & 4 & 8 & 12 & 16 & 20 \\
\hline$\Xi=0$ & 0 & 0 & 0 & 0 & 0 \\
$\Xi=1, \phi_{g}=0$ & -0.014 & -0.077 & -0.102 & -0.115 & -0.123 \\
$\Xi=1, \phi_{g}=.50$ & 0.001 & -0.027 & -0.037 & -0.043 & -0.046 \\
$\Xi=1, \phi_{g}=1$ & 0.014 & 0.015 & 0.015 & 0.015 & 0.015 \\
IT,$\pi^{n}$ & -0.016 & -0.011 & -0.010 & -0.009 & -0.009 \\
IT, $\pi^{C O R E}$ & -0.014 & -0.010 & -0.009 & -0.009 & -0.008 \\
IT,$\pi^{C P I}$ & -0.019 & -0.015 & -0.014 & -0.014 & -0.013
\end{tabular}

Table 3: Welfare as a Function of $\omega$

\begin{tabular}{lccccccc}
$\omega$ & 1 & 2 & 3 & 4 & 5 & 6 & 7 \\
\hline$\Xi=0$ & 0 & 0 & 0 & 0 & 0 & 0 & 0 \\
$\Xi=1, \phi_{g}=0$ & 0.060 & -0.102 & -0.125 & -0.135 & -0.141 & -0.145 & -0.148 \\
$\Xi=1, \phi_{g}=.50$ & 0.029 & -0.037 & -0.053 & -0.060 & -0.064 & -0.067 & -0.069 \\
$\Xi=1, \phi_{g}=1$ & 0.017 & 0.015 & 0.015 & 0.014 & 0.014 & 0.014 & 0.014 \\
IT,$\pi^{n}$ & -0.011 & -0.010 & -0.009 & -0.009 & -0.009 & -0.008 & -0.008 \\
IT, $\pi^{C O R E}$ & -0.011 & -0.009 & -0.008 & -0.008 & -0.008 & -0.007 & -0.007 \\
IT,$\pi^{C P I}$ & -0.015 & -0.014 & -0.014 & -0.013 & -0.013 & -0.013 & -0.013
\end{tabular}


Table 4: Welfare as a Function of $\sigma_{m}$

\begin{tabular}{lccc}
$\sigma_{m}$ & 0.25 & 0.75 & 1.50 \\
\hline$\Xi=0$ & 0 & 0 & 0 \\
$\Xi=1, \phi_{g}=0$ & 0.053 & -0.102 & -0.541 \\
$\Xi=1, \phi_{g}=.50$ & 0.034 & -0.037 & -0.177 \\
$\Xi=1, \phi_{g}=1$ & 0.014 & 0.015 & 0.016 \\
IT, $\pi^{n}$ & -0.004 & -0.010 & -0.020 \\
IT, $\pi^{C O R E}$ & -0.004 & -0.009 & -0.017 \\
IT, $\pi^{C P I}$ & -0.004 & -0.014 & -0.029
\end{tabular}

Table 5: Welfare as a Function of $\alpha_{\pi}$

\begin{tabular}{lcccccccccc}
$\alpha_{\pi}$ & 1.01 & 1.1 & 1.25 & 1.5 & 1.75 & 2 & 5 & 10 & 100 & 10000000 \\
\hline IT, $\pi^{n}$ & -0.210 & -0.035 & -0.016 & -0.010 & -0.008 & -0.007 & -0.004 & -0.004 & -0.004 & -0.004 \\
IT, $\pi^{C O R E}$ & -0.210 & -0.031 & -0.015 & -0.009 & -0.007 & -0.006 & $\mathrm{x}$ & $\mathrm{x}$ & $\mathrm{x}$ & $\mathrm{x}$ \\
IT, $\pi^{C P I}$ & -0.310 & -0.048 & -0.023 & -0.014 & -0.011 & -0.010 & $\mathrm{x}$ & $\mathrm{x}$ & $\mathrm{x}$ & $\mathrm{x}$
\end{tabular}

Table 6: Calibrated Parameters and Steady State Values

$\begin{array}{lclc}\text { Parameter } & \text { Value } & \text { Parameter } & \text { Value } \\ \tau & .50 & \sigma_{u} & .50 \\ \sigma_{c} & .50 & \sigma_{s} & .25 \\ \sigma_{m} & .75 & \beta & .25 \\ \Omega & 3 & \rho & .05 \\ \omega & 2 & \alpha & .10 \\ \delta_{d} & .10 & \sigma_{t} & .50 \\ \sigma_{n} & .50 & m_{o} & .08 \\ F_{o} & .12 & E_{o} & .75 \\ P_{o}^{d} I_{o}^{d} & .20 & \mathscr{P}_{o}^{o} O_{o}^{h} & .05 \\ P_{o}^{o} O_{o}^{t} & .03 & P_{o}^{o} O_{o}^{n} & .03\end{array}$


Figure 1: Full Pass Through
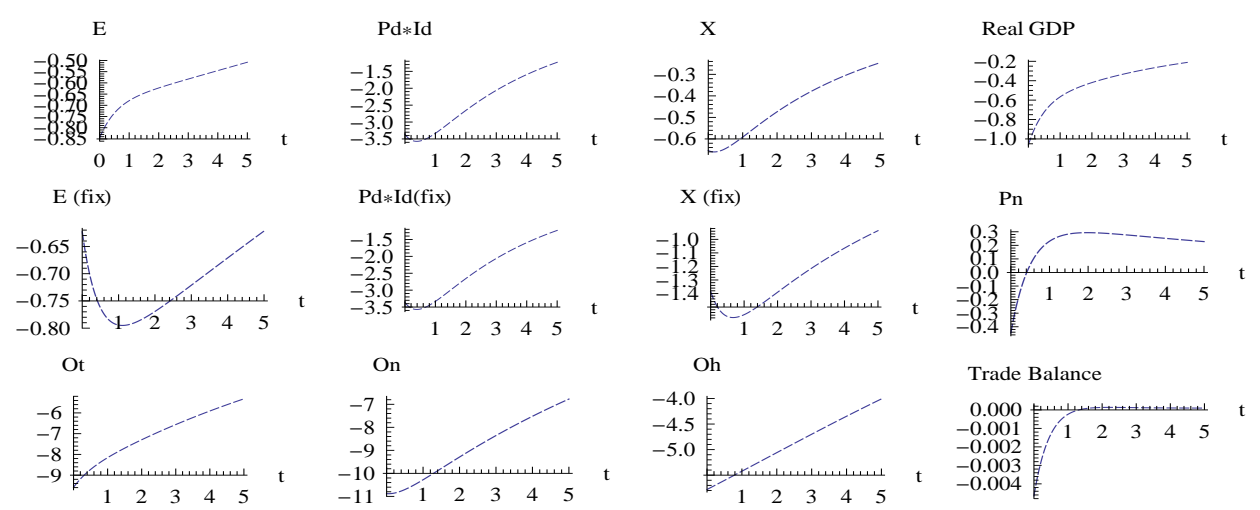

$$
\text { Lt }
$$
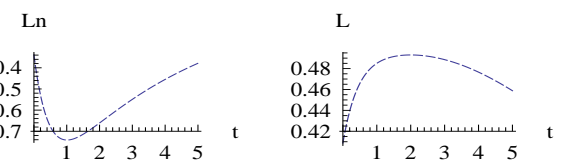

W
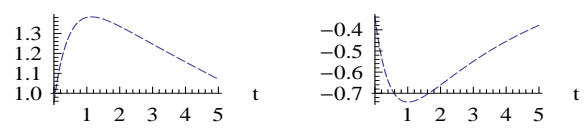

Qt
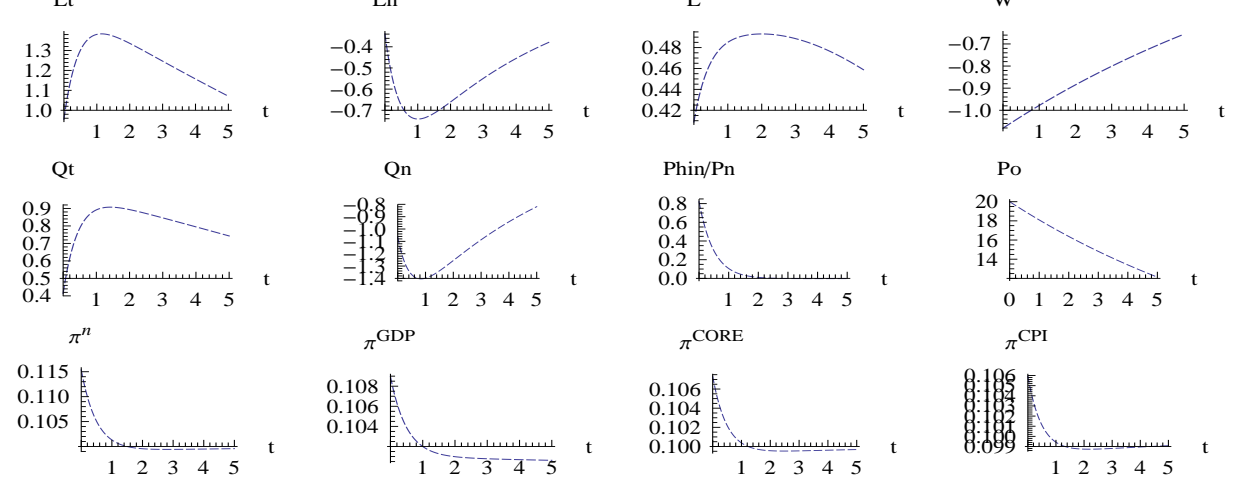

F
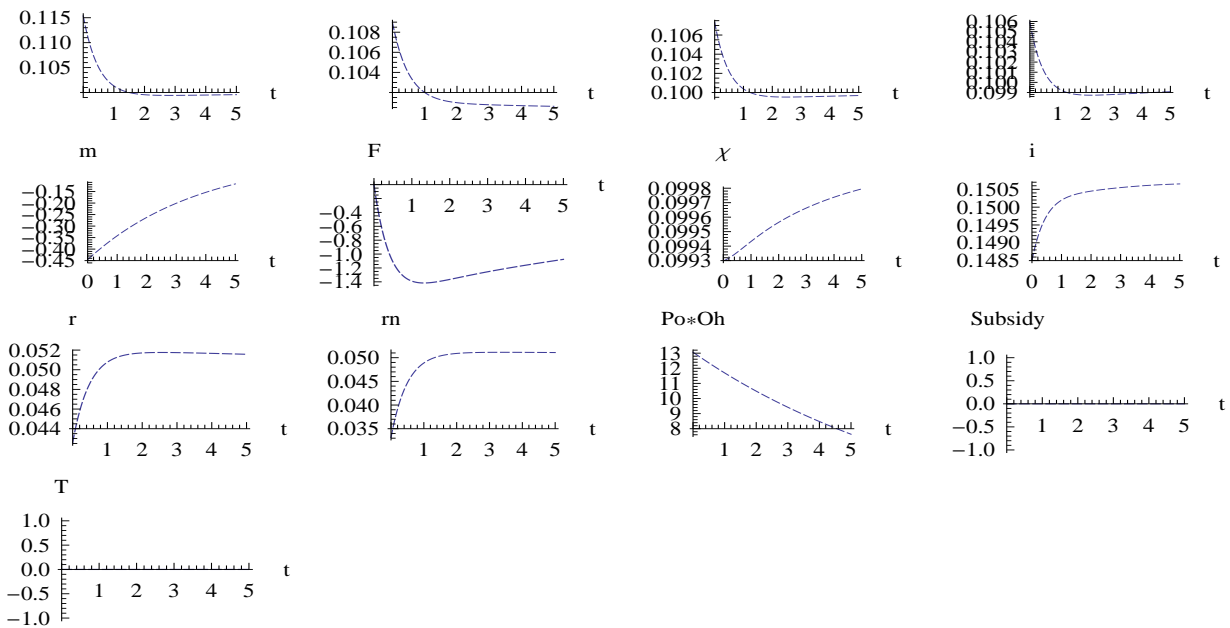
Figure 2: No Pass Through, $\phi_{g}=1$
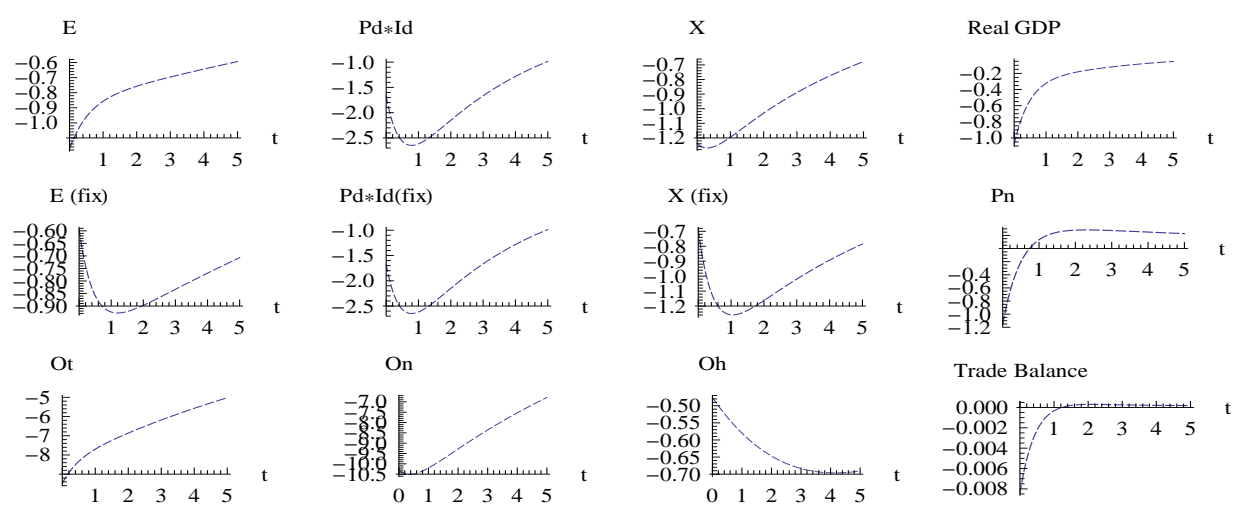

Lt
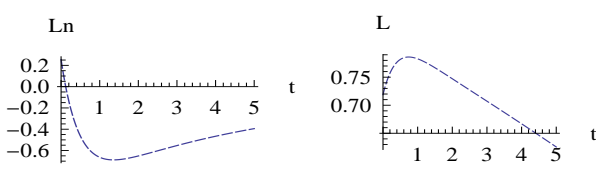

$\mathrm{W}$

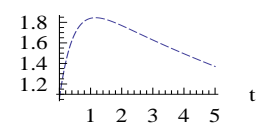

Qt

Qn

Phin/Pn
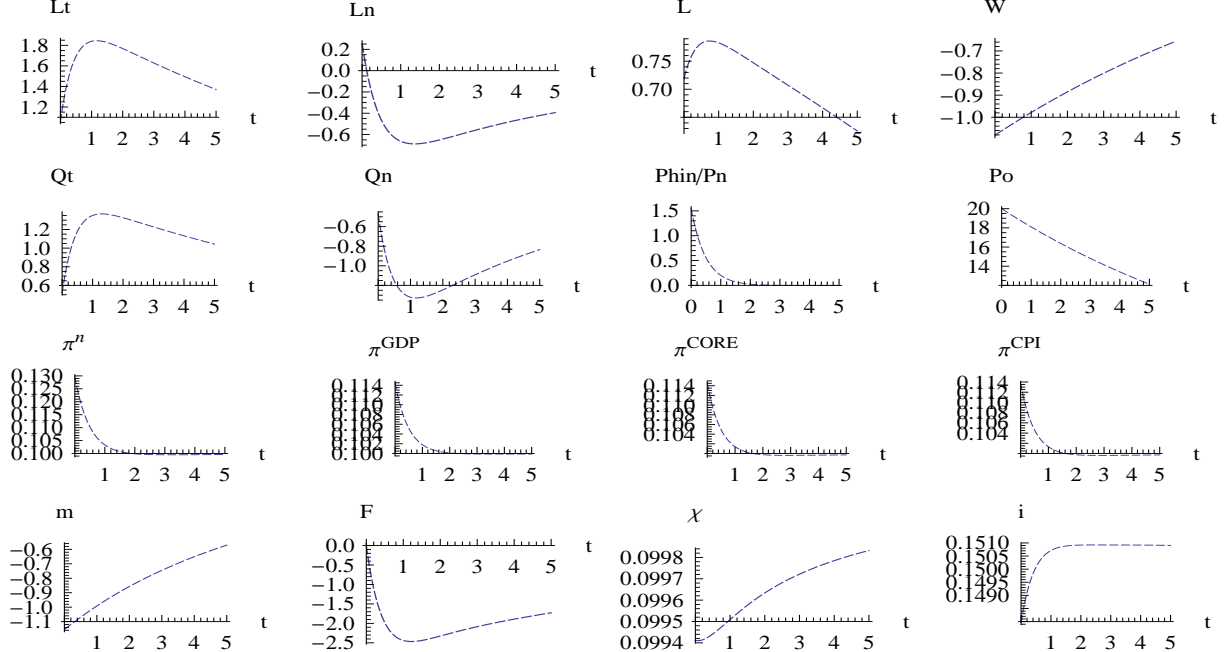

F
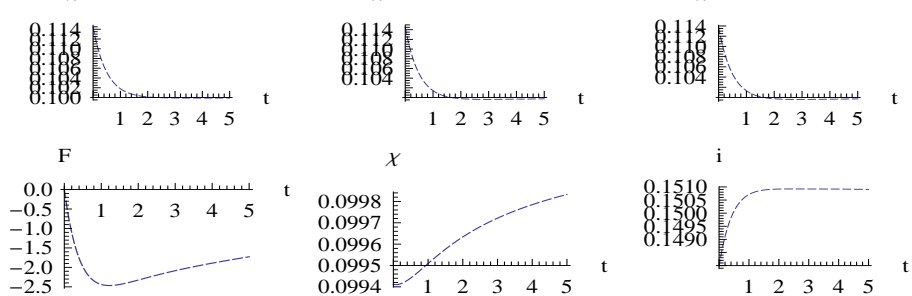

rn
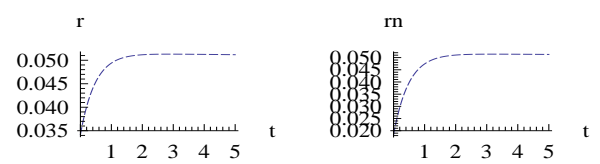
$\mathrm{T}$
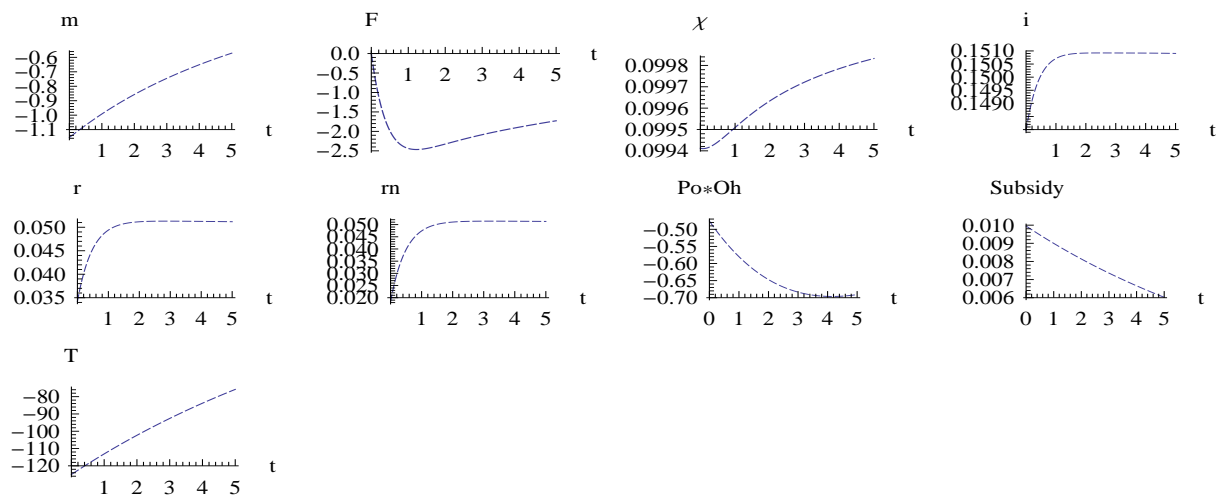
Figure 3: No Pass Through, $\phi_{g}=0$
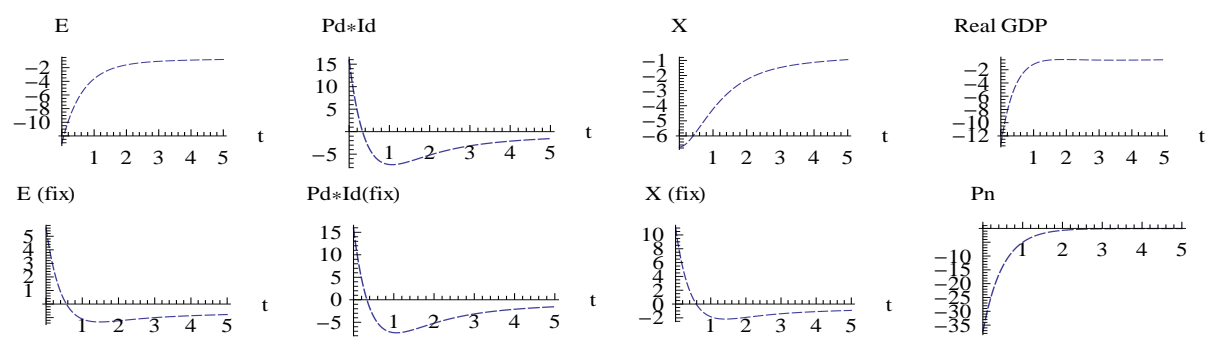

$\mathrm{X}$ (fix)

$\begin{array}{r}10 \\ 8 \\ 4 \\ 2 \\ \hline\end{array}$

Ot
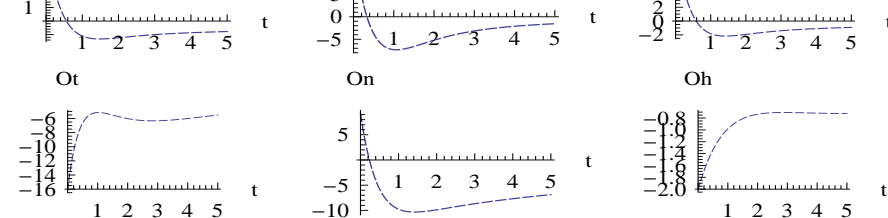

Lt
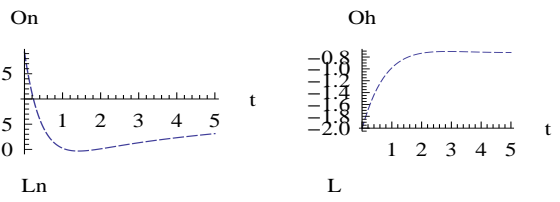

Pn

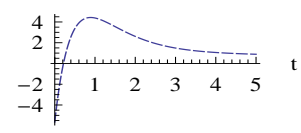

Ln

L

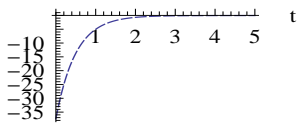

Trade Balance
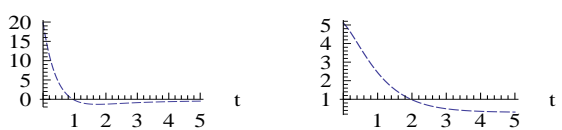

0.02
0.00
-0.02
-0.04
-0.06
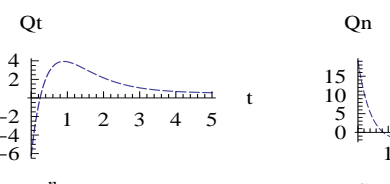

Phin/Pn

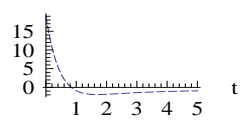

50 臬
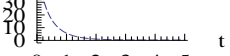

$\pi^{n}$ $\pi^{\mathrm{GDP}}$
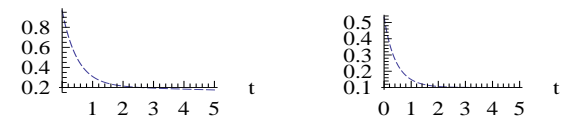

$\pi^{\text {CORE }}$

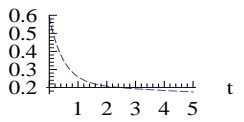

W
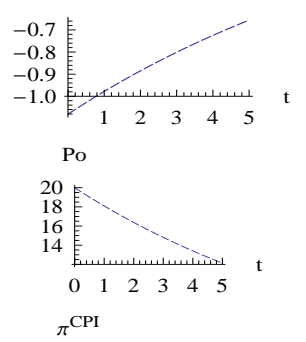

m

F

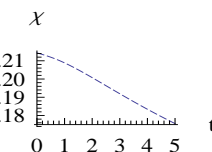

0.5
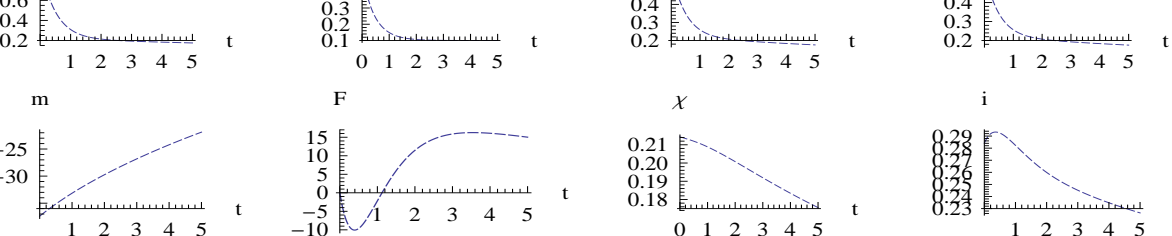

rn

$\mathrm{Po} * \mathrm{Oh}$
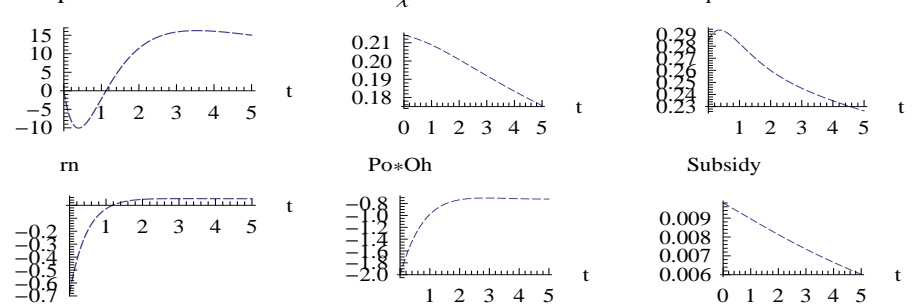

Subsidy

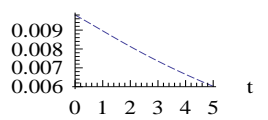

$\mathrm{T}$

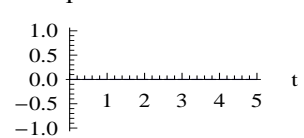


Figure 4: No Pass Through, $\phi_{g}=0.50$
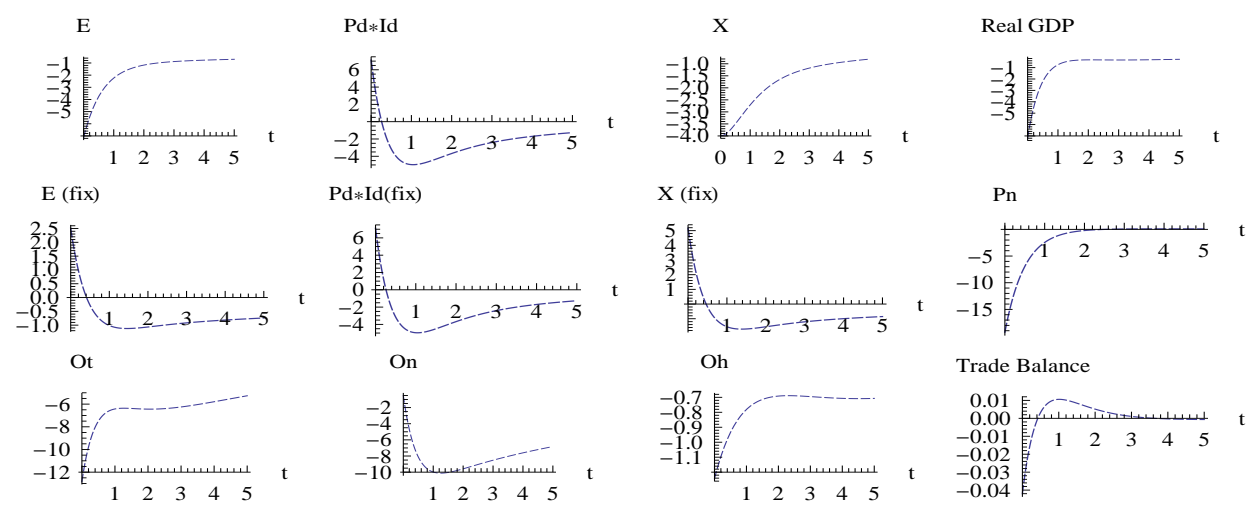

Trade Balance

Lt

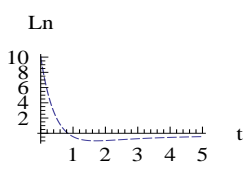

L

0.01 E.-.

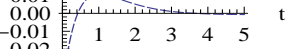

-0.01 㲀

$-0.02$

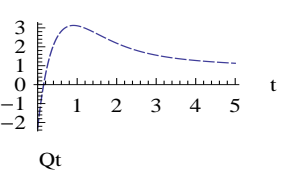

Qn

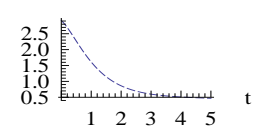

W

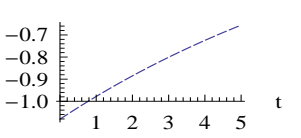

Phin/Pn
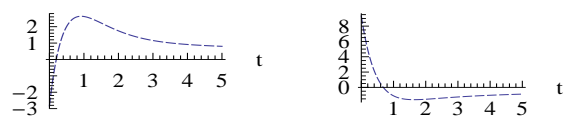

25
20
15
10
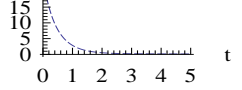

$\pi^{n}$
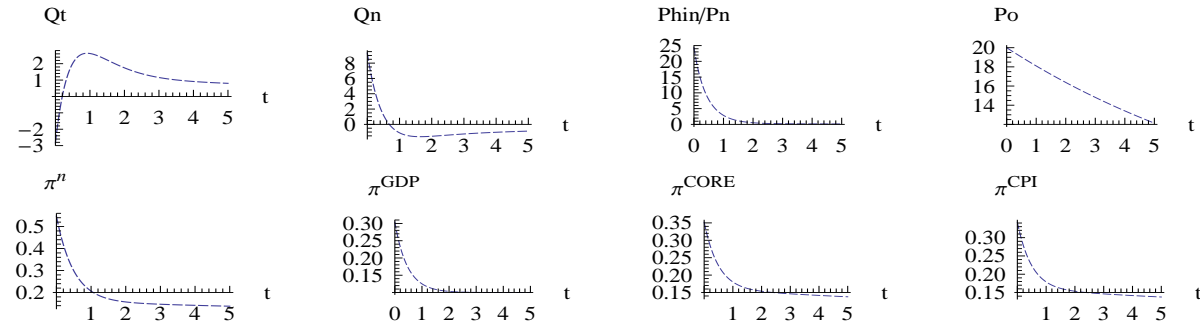

m

F

x
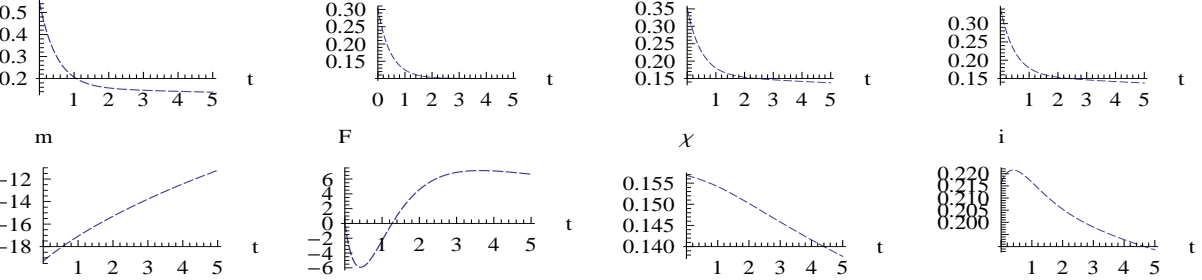

rn

$\mathrm{Po} * \mathrm{Oh}$
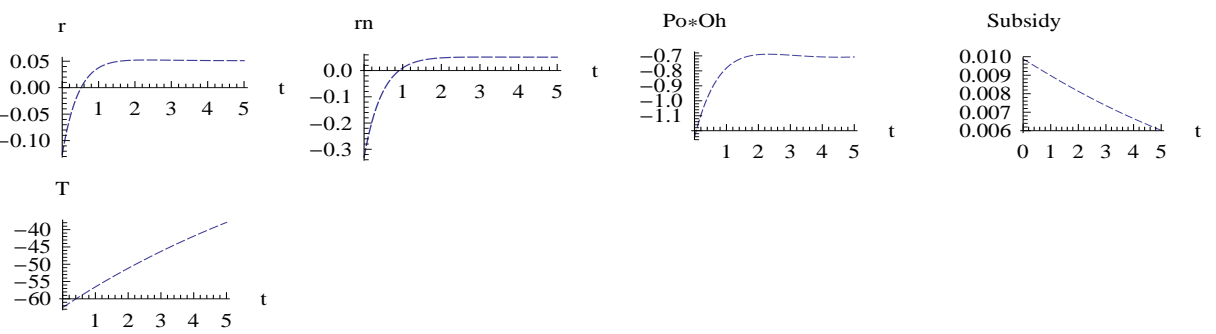
Figure 5: Non-Traded Inflation
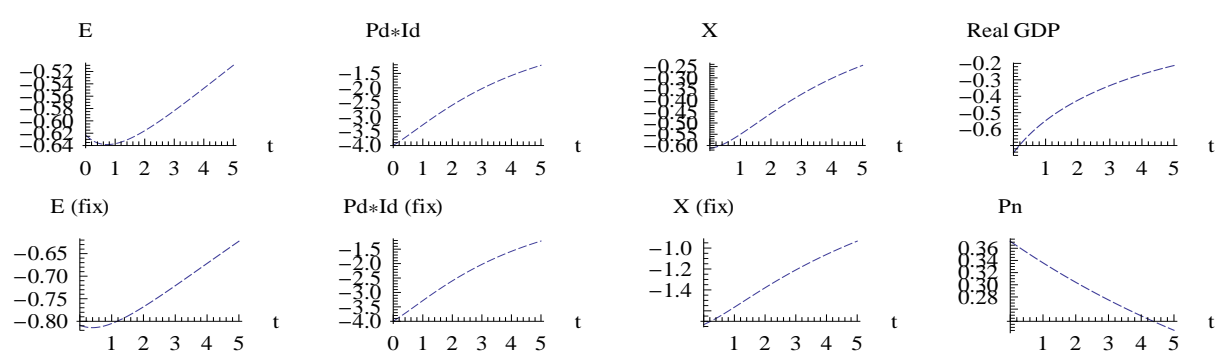

$\mathrm{Pd} *$ Id (fix)
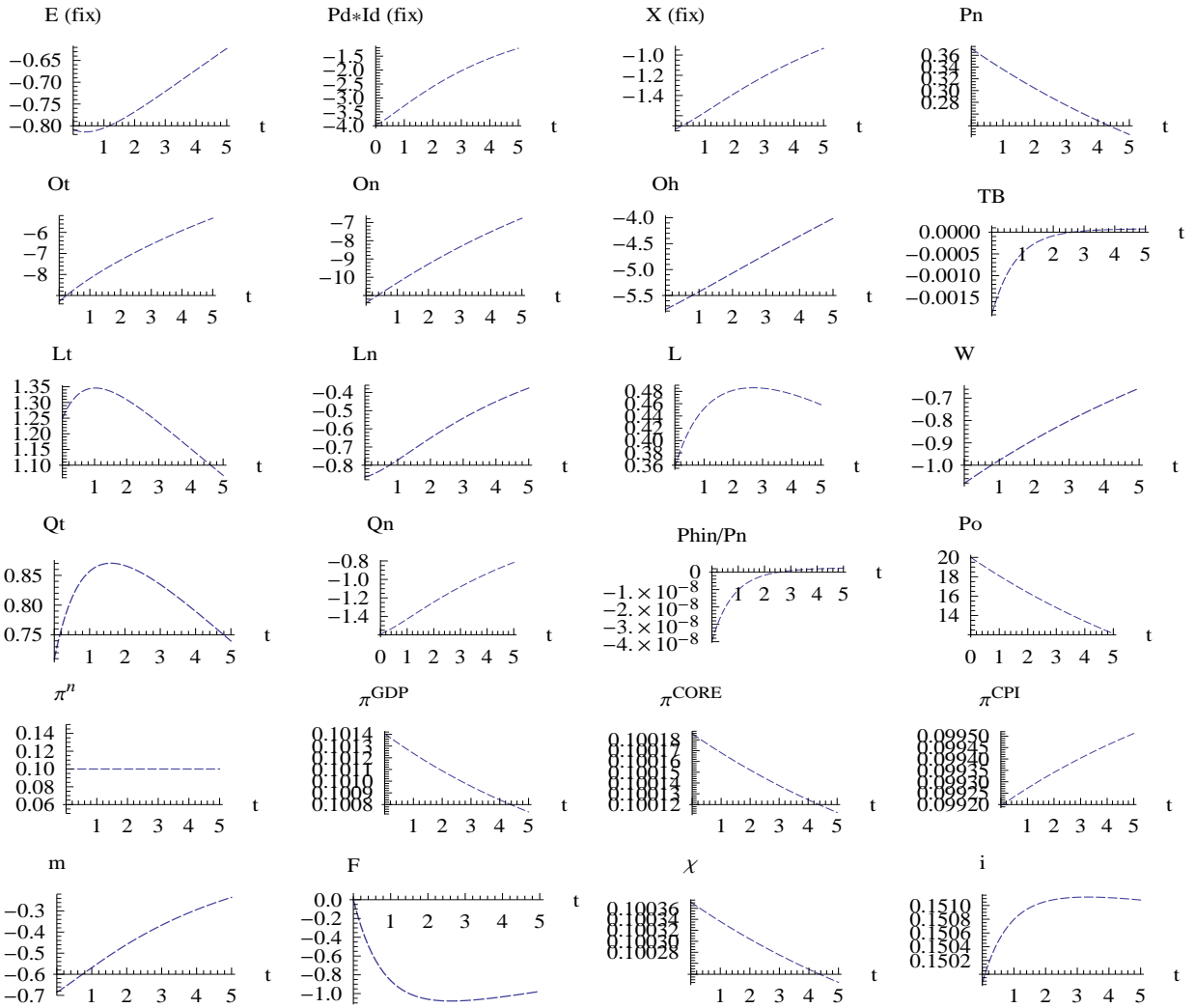

rn
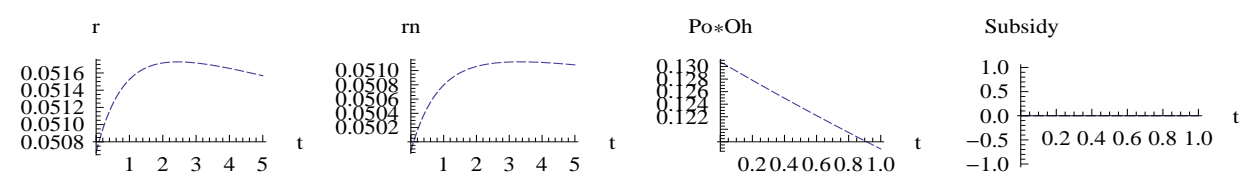
Figure 6: Core Inflation
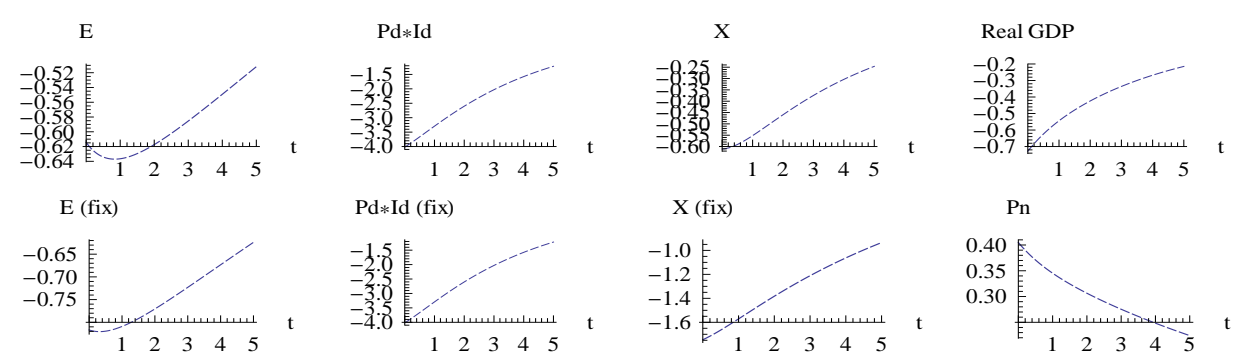

Pd $*$ Id (fix)

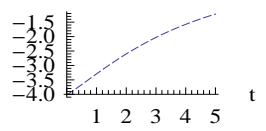

$\mathrm{X}$ (fix)
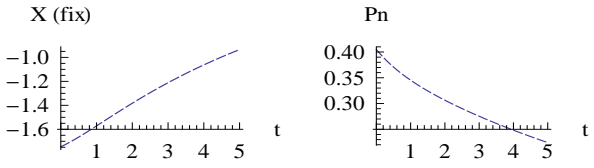

Ot
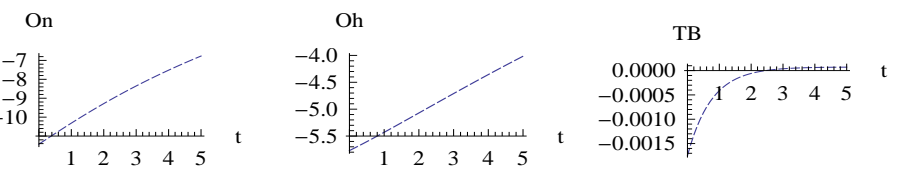

Lt

$$
\text { Ln }
$$

L

W
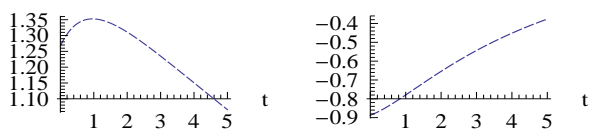

Qt
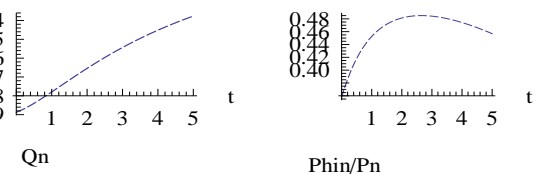

Phin/Pn
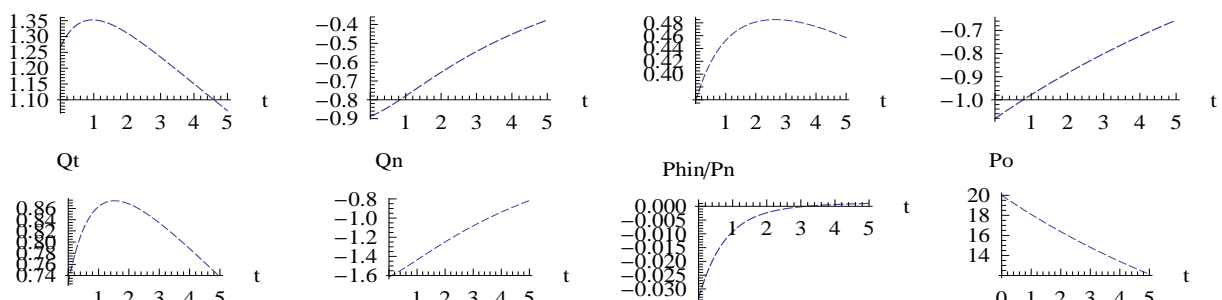

$\pi^{n}$
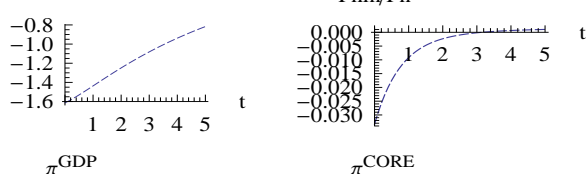

$\pi^{\mathrm{CORE}}$
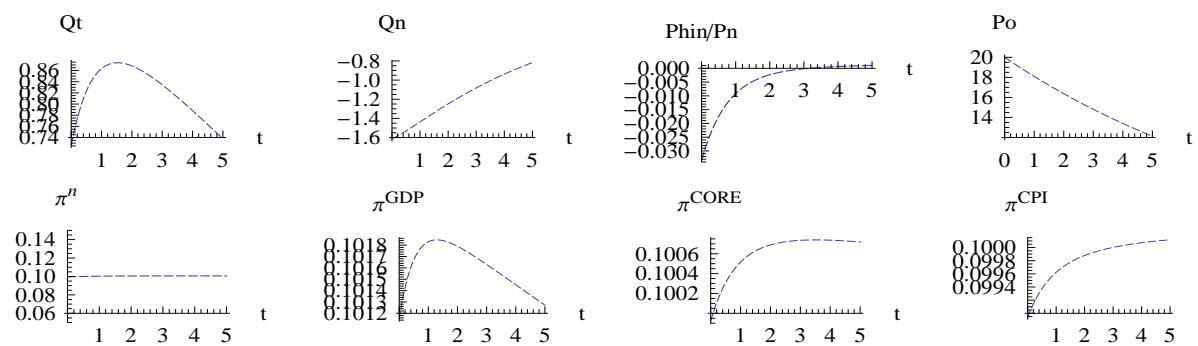

$\mathrm{m}$

F
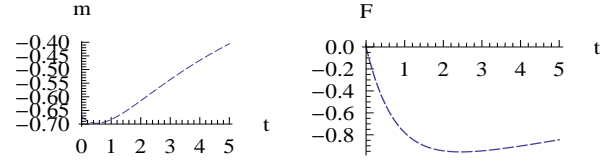

rn
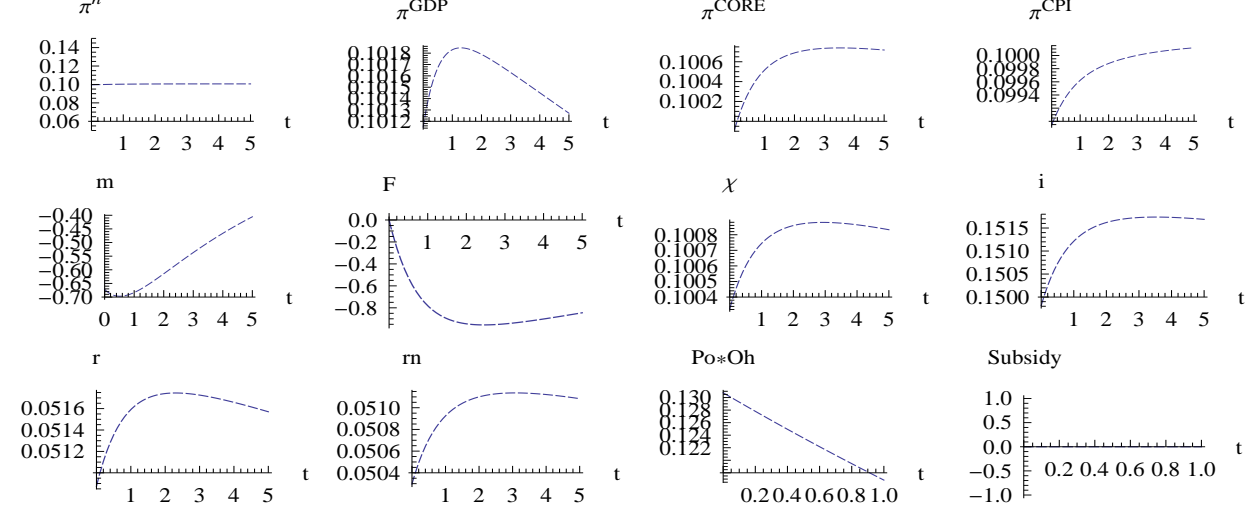


\section{References}

Bacon, R., And M. Kojima (2006): "How are Developing Countries Coping with Higher Oil Prices?," World Bank, ESMAP report.

Baig, T., A. Mati, D. Coady, and J. Ntamatungiro (2007): "Domestic Petroleum Product Prices and Subsidies: Recent Developments and Reform Strategies," IMF Working Paper, WP/07/71.

Bernanke, B. S. (1985): "Adjustment Costs, Durables, and Aggregate Consumption," Journal of Monetary Economics, 15, 41-68.

Bodenstein, M., C. Erceg, And L. Guerrieri (2008): "Optimal Monetary Policy with Distinct Core and Headline Inflation Rates," Journal of Monetary Economics, forthcoming.

Bouakez, H., N. Rebei, and D. Vencatachellum (2008): "Optimal Pass-Through of Oil Prices in an Economy with Nominal Rigidities," CIRPEE Working Paper.

Burstein, A. T., J. C. Neves, and S. Rebelo (2003): "Distribution costs and real exchange rate dynamics during exchange-rate based stabilizations," Journal of Monetary Economics, 50, 1189-1214.

Calvo, G. A. (1983): "Staggered Prices in a Utility-Maximizing Framework," Journal of Monetary Economics, 12, 383-398.

Coady, D., M. El-Said, R. Gillingham, K. Kpodar, P. Medas, and D. NewHOUsE (2006): "The Magnitude and Distribution of Fuel Subsidies: Evidence from Bolivia, Ghana, Jordan, Mali, and Sri Lanka," IMF Working Paper, WP/06/247.

DhaWAn, R., And K. Jeske (2007): "Taylor Rules with Headline Inflation: A Bad Idea!," Working Paper.

Dudine, P., J. John, M. Lewis, L. Monasi, H. Tadesse, and J. Zeuner (2006): "Weathing the Storm So Far: The Impact of the 2003-05 Oil Shock on Low-Income Countries," IMF Working Paper, WP/06/171.

IMF (2006): "Regional Economic Outlook: Sub-Saharan Africa," IMF publication.

_ (2008a): "Food and Fuel Prices - Recent Developments, Macroeconomic Impact, and Policy Responses," IMF Working Paper.

(2008b): "IMF Survey," IMF publication.

(2008c): "IMF Survey," IMF publication.

(2008d): "The Balance of Payments Impact of the Food and Fuel Price Shocks on Low-Income African Countries: A Country-by-Country Assessment," IMF Working Paper.

Leduc, S., AND K. SILl (2004): "A Quantitative Analysis of Oil-Price Shocks, Systematic Monetary Policy, and Economic Downturns," Journal of Monetary Economics, 51, 781808. 
Plante, M. (2009a): "How Should Monetary Policy Respond to Changes in the Relative Price of Oil?," Working Paper.

(2009b): "Monetary Policy, Exchange Rates, and Oil Price Shocks in an Economy with Traded and Non-Traded Goods," Working Paper.

(2009c): "Two Calvo Pricing Models for Continuous Time, Open Economy Models with Traded and Non-Traded Goods," Notes.

WAllis, D. (2007): "Africa weathers record oil prices for now," Reuters. 
Figure 7: CPI Inflation
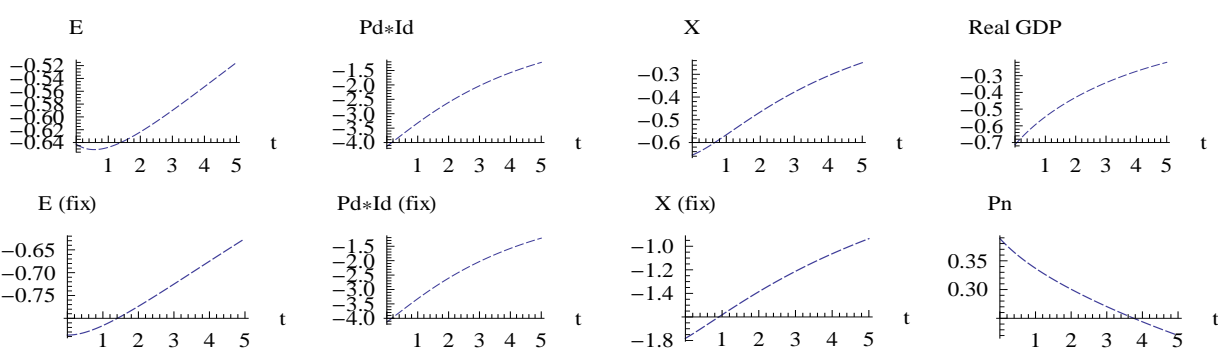

$\mathrm{Pd} * \mathrm{Id}$ (fix)
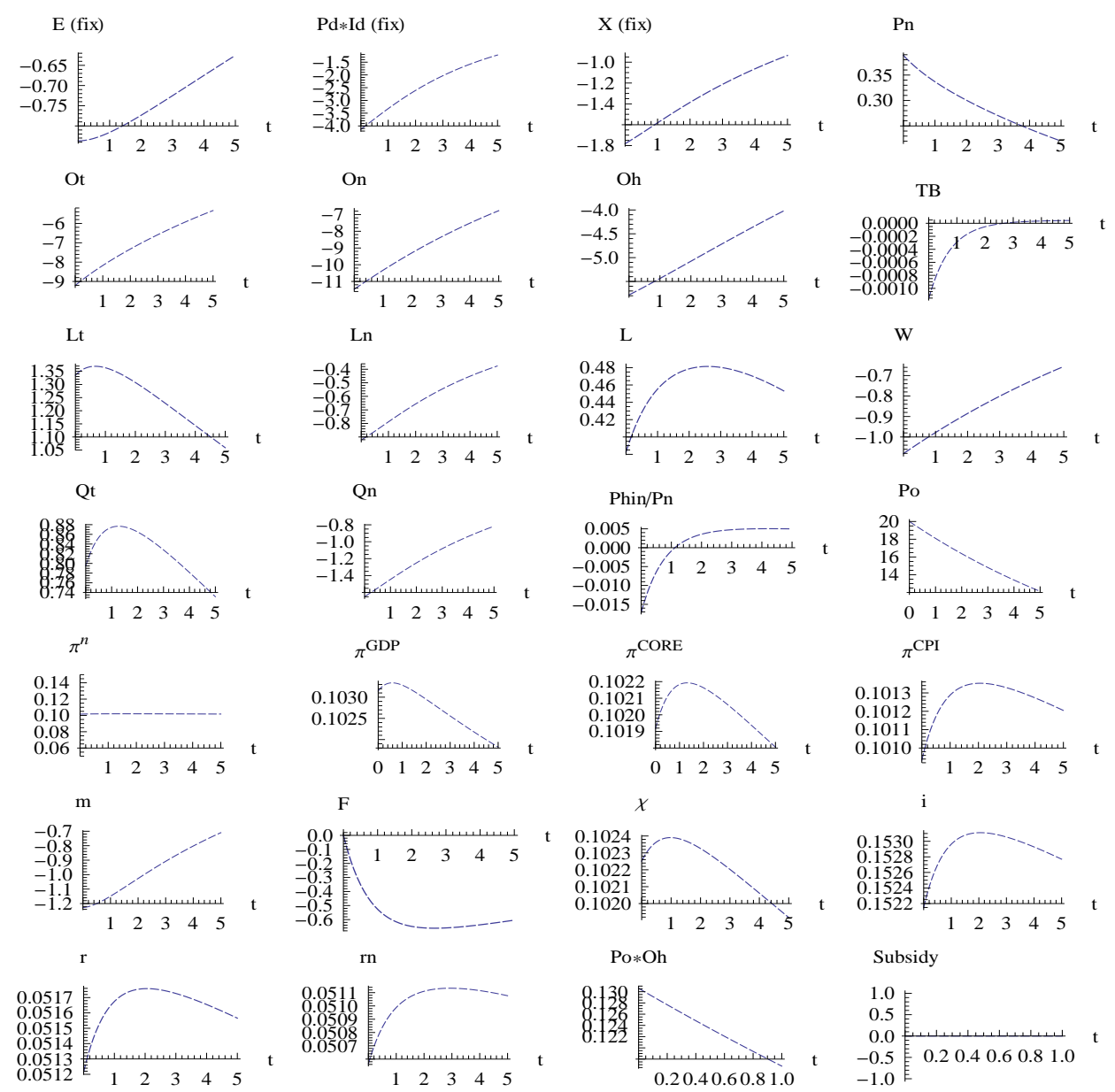